\title{
A Decision-Making Approach for Ranking Tertiary Institutions' Service Quality Using Fuzzy MCDM and Extended HiEdQUAL Model
}

\author{
Olufunke Oladipupo $\mathbb{D}{ }^{1},{ }^{1}$ Taiwo Amoo $\mathbb{D}^{1},{ }^{1}$ and Olawande Daramola $\mathbb{D}^{2}$ \\ ${ }^{1}$ Department of Computer Science, College of Science and Technology, Covenant University, Ota, Ogun State, Nigeria \\ ${ }^{2}$ Cape Peninsula University of Technology, Cape Town, South Africa \\ Correspondence should be addressed to Olufunke Oladipupo; funke.oladipupo@covenantuniversity.edu.ng
}

Received 3 May 2021; Revised 13 October 2021; Accepted 27 October 2021; Published 29 November 2021

Academic Editor: Sebastian Ventura

Copyright (c) 2021 Olufunke Oladipupo et al. This is an open access article distributed under the Creative Commons Attribution License, which permits unrestricted use, distribution, and reproduction in any medium, provided the original work is properly cited.

\begin{abstract}
The attainment of excellence in institutions is maintained through the institutions' adherence to its core values and efficient service delivery. These factors are very important in facilitating global development of a country and determining the world ranking of an institution. To this effect, this study presents an effective approach for evaluating and ranking quality of services in a higher institution, taking four higher institutions in Nigeria as case studies. Service quality consists of different attributes and many of them are intangible and difficult to measure, which means that using the previously known measurement approach will be insufficient. Therefore, a fuzzy method was proposed to resolve the ambiguity of the concepts and intra-uncertainty, which are associated with human judgments in decision-making. This study adopted a contextualized service quality model for educational domain called HiEdQUAL with some extended criteria in order to evaluate the perception of service quality by respondents from the selected higher institutions: two private universities and two public universities from the south-west region of Nigeria. Four Multi-Criteria Decision-Making (MCDM) methods: TOPSIS, Yager's min-max, Compensatory AND, and Ordered Weighted Averaging are applied to comparatively evaluate the quality of services in the four higher institutions. The MCDM methods are engaged independently to validate the reliability of the ranking results. The importance weight of each performance criterion is found with Fuzzy Analytical Hierarchy Process (FAHP) algorithm. This study has been able to practically establish ExtHiEdQUAL as a new service quality model for higher education with six concepts and 33 criteria. The output of the Fuzzy MCDM ranking recommends institution $B$ as the best institution to students based on the Ext-HiEdQUAL measures. Also, findings from the sensitivity analysis showed that Yager's min-max outperform the other investigated methods in this study by being consistent and exceptionally tolerant in most instances when there is significant deviation in criteria weights.
\end{abstract}

\section{Introduction}

Tertiary institutions are pivotal in driving the economic growth and sustainability of a nation. Generally, most governments in developing countries disburse funds to public higher institutions so that tuition fees for students are subsidized, unlike what happens in private institutions where the cost of tuition is higher. This mode of government's financial support is geared towards improving the quality of service being rendered by these institutions to their primary customers (students), which in turn leads to an increase in student subscription, creation of more values, and higher excellence [1]. It has been observed that students, being the primary customers of every higher institution across all degree levels, prefer to choose a university that has evidence of quality service delivery and a global reputation [2]. In Ref. [3], service quality was defined as the capacity of an organization to equal or surpass the customers' expectations. It is usually quite tasking when the students have to do an evaluation in order to select the best institutions from a set of alternatives. In such cases, ranking the alternative institutions based on their merits in order to make a good 
decision becomes imperative. Hence, the Multi-Criteria Decision-Making (MCDM) methods become useful in evaluating and ranking institutions.

MCDM refers to making decisions in the presence of multiple, incommensurable, and conflicting criteria $[4,5]$. MCDM can be broadly classified into 2 categories which are the Multi-Attribute Decision-Making (MADM) and MultiObjective Decision-Making (MODM) [6-10]. MADM belongs to a class of methods that solve decision-making problems that are discrete in nature, i.e., have finite number of alternatives to be evaluated, while the MODM approach, on the other hand, encompasses methods that deal with decision-making problems that are nondeterministic in nature, whereby the decision space is continuous and alternatives are infinite [11-13]. Hence, evaluation of quality of service (QoS) in higher institutions is considered a MADM problem due to its finite number of alternatives. In Ref. [14], a hybrid MCDM method for performance evaluation of private universities in Taiwan was presented using AHP to weigh the performance evaluation indices and the VIKOR method in ranking the private universities. The work was structured to be geographically context-specific to universities in Taiwan. Ref. [15] proposed a fuzzy AHP for ranking the performances of five UK universities with respect to 4 criteria. In Ref. [16], a study was presented that utilized the AHP and TOPSIS in the evaluation of performance of schools. Parents were used as the determinants of the performance of each criterion as the ranking was not based on higher institutions but was on high schools. The work in Ref. [17] developed a web-based support system using the MCDM method-ELECTREIII-in the personalized ranking of British Universities. In Ref. [18], VIKOR was employed as the MCDM method in the ranking of universities in Turkey based on academic performance only. The authors in Ref. [19] presented the use of TOPSIS with Fuzzy type-2 for managing the choice of a university. However, these studies have not considered the comparative evaluation of different methods to ascertain the reliability of the ranked results, thereby, resulting in bias as a result of the selection of a single method for ranking.

Over the years, researchers have proposed a number of state-of-the-art service quality models as evaluation index for assessing performance in Higher Education [3, 20-22]. SERVQUAL model proposed by Ref. [3] with five-dimensional constructs consisting of tangible, reliability, responsiveness, assurance, and empathy has been widely utilized in the industry and educational sectors. This is based on the customers' expectations minus the customers' perceptions. According to Ref. [22], SERVQUAL was reported to answer strongly to the marketing sector but to a lesser extent to the higher education learning sector. The connotation from research is that students who are the primary customers for higher education do not have a well-constructed body of knowledge (imprecision) about expectations of a university [23]. In Ref. [20], another variant of the SERVQUAL model, called the SERVPERF, was proposed. SERVPERF was found to be more psychometrically sound compared to the SERVQUAL. However, its diagnostic power is questionable because it does not provide in-depth insight to the manager about the shortfalls in the quality of service rendered [24]. In response to this, other researchers have proposed contextualized service quality models for education using service characteristic and features in higher education [21, 25-28]. HedPERF (Higher Education PERFormance-only) was proposed with six dimensional constructs that consist of nonacademic aspects, academic aspects, reputation, access, program issues, and understanding [21]. However, it uses a SERVPERF paradigm, which is adjudged to have less diagnostic power [24]. Furthermore, SQM-HEI was developed as an instrument for measuring service quality in a tertiary institution [22]. SQM-HEI established three dimensions, which are best faculty, excellent physical resources, and wide range of disciplines and placement. However, this is not robust because it scarcely considers nonacademic aspects of services rendered in higher institutions. In Ref. [27], HiEdQUAL was proposed with five dimensions consisting of teaching and course content, administrative services, academic facilities, campus infrastructure, and support services within the higher education sector. In Ref. [28], six dimensional constructs were used, which consist of lecturers (teaching and learning), curriculum, administration, facilities, library, and Islamic environment. However, the HiEdQUAL was limited in its practicability since some of the criteria were not contextualized to universities in subSaharan Africa. Therefore, it did not meet the aspirations of the students in sub-Saharan universities.

In summary, evidence from the literature reveals that first, service quality dimensions vary depending on the research objectives, author's perspective, institutional environment, and target customers [28]. Secondly, so far, the service quality models that have been proposed for the educational context did not consider the hierarchical order of importance of criteria dimensions used for evaluation of service quality in tertiary institutions, which limits their practical relevance [16-19]. Thirdly, the models were utilized to measure service quality by selecting a single ranking MCDM method, without considering how to handle the issue of human subjectivity and the reliability of ranked results when evaluating competing alternatives, which is also a limiting factor that can result in bias [29].

Therefore, these shortcomings are addressed when evaluating service quality in higher institutions in this study. Hence, a fuzzy MCDM approach is proposed to evaluate and rank quality of service in four Nigerian higher institutions based on Ext-HiEdQUAL. The following commonly used four MCDM methods, TOPSIS, Yager's min-max, Compensatory AND, and Ordered Weighted Averaging, were proposed to comparatively evaluate and rank service quality in four Nigerian higher institutions. Fuzzy MCDM will (1) enable handling of subjectivity in the evaluation of competing alternatives; (2) cater to the hierarchical order of importance of criteria dimensions that makeup the service quality model used for evaluation; and (3) demonstrate the reliability of the ranked results by comparing results from four MCDM methods and show the stability of each of the MCDM methods by employing sensitivity analysis.

The extended HiEdQUAL (Ext-HiEdQUAL) model incorporates the Internationalisation dimension in order to 
derive a more robust model to evaluate service quality in higher education. The extended model consists of six dimensions that are contextualized for education, namely, teaching and course content, administrative services, academic facilities, campus infrastructure, support services, and Internationalisation. The extension was necessary because: (1) the ranking criteria attributes for the global ranking of higher intuitions by Times Higher Education (https://www. timeshighereducation.com/world-university-rankings/ world-university-rankings-2020-methodology) includes two service delivery factors, which are Teaching Content and internationalisation; (2) according to Refs. [1, 30], lack of adequate internationalisation is a major drawback of institutions in many developing countries, particularly Nigerian institutions, which constitute the study context for this research.

The main contributions are:

(1) Extending an existing HiEdQUAL service quality model with Internalization dimension to meet the need for globalization in Higher institution ranking.

(2) A comparative evaluation of four fuzzy MCDM methods to validate reliability of the ranked results using a contextualized extended HiEdQUAL model for measuring quality of service in higher institutions. These MCDM methods combine fuzzy set theory to handle subjectivity from decision-makers in the evaluation of alternatives.

(3) A sensitivity analysis of the proposed four fuzzy MCDM methods to ascertain its impact on the ranking of the alternatives and the stability of each MCDM method.

(4) It also outlines the importance of each service quality factor in the context of the four Nigerian universities by revealing each institution's weak and strong points quantitatively, and ranking the institutions accordingly, based on multiple service quality performance criteria.

The remaining part of this paper is as follows. In Section 2 , an extensive literature review was carried out. In Section 3, the methodology was explicitly described while in Section 4 , we present the result and discussion. Section 5 presents a report of sensitivity analysis that compares results of the four MCDM methods with established finding from the literature. The paper is concluded in Section 6 with a summary and overview of future work.

\section{Literature Review}

In Ref. [3], service quality was defined as the capacity of an organization to equal or surpass the customers' expectations. It is usually quite tasking when the students as customers have to do an evaluation in order to select the best institutions from a set of alternatives (institutions). In such cases, it is important to sort, describe, or do a ranking of the alternatives in order to make a good decision or recommendation. In this situation, the Multi-Criteria DecisionMaking (MCDM) methods become useful. MADM-based
MCDM methods are sectioned into two categories, which follow human aggregation processes in evaluation of an alternative. This is either by compensatory means, which considers all criteria performance values in choosing an optimal alternative which is termed "Multi-Attribute Utility Theory" (MAUT), or noncompensatory means which is termed "Outranking Approach." The Outranking Approach allows compromise between criteria values and can have an element of unforeseen bias in its recommendations [31]. Hence, the MAUT methods of the MCDM classification are integrated in this work because it aggregates and takes into consideration all the criteria performance values in estimating an overall performance value for each alternative.

MCDM techniques have the capacity for alternatives to be measured explicitly through objective and subjective judgments of a decision-maker. Each method is only unique in how it combines its data and can therefore give different ranking results $[32,33]$. MCDM has the capability to accommodate both quantitative and qualitative measurement of criteria. This has made it suitable for evaluating service quality in different sectors, including educational sector, especially when the performance evaluation problem is qualitative in nature. In evaluating alternatives using numerical analysis, the MCDM method follows three important steps: (i) determine the criteria and alternatives; (ii) determine the weights for each criterion to show order of importance and the scores of each criterion with respect to the alternative; and (iii) process the numerical values to aid in ranking of the alternatives [32].

However, in the real world, opinions differ and consist of uncertainties when measurement is made under human consideration. This is not any different in the evaluation of service quality. Therefore, in order to handle the subjectivity and uncertainty in the opinions of decision-makers, Fuzzy Set theory becomes essential for the MCDM process for modeling the decision-makers' opinions [34]. The incorporation of Fuzzy Set theory allows the use of linguistic variables like Fair, Strong, and Very Strong and the like, and membership values in measuring the satisfaction level anticipated for each criterion with respect to the alternative concerned, Hence, in considering the subjectivity and uncertainty in the opinions of decision-makers for evaluating the service quality of higher institutions in Nigeria, a Fuzzy Multi-Criteria Decision-Making (Fuzzy MCDM) approach is appropriate.

Researchers have contributed immensely in the area of using different MCDM methods for the evaluation of alternatives [35-44]. Fuzzy MCDM models have been reported as widely used approaches in decision-making processes [45]. In Ref. [14], a hybrid MCDM method for performance evaluation of private universities in Taiwan was presented using AHP to weigh the performance evaluation indices and the VIKOR method in ranking the private universities. However, the work was structured to be geographically context-specific to universities in Taiwan. In Ref. [16], a study was presented that utilized the AHP and TOPSIS in the evaluation of performance of schools. Parents were used as the determinants of the performance of each criterion as the ranking was not based on higher institutions but was on high schools. The 
work in Ref. [17] developed a web-based support system using the MCDM method- ELECTREIII-in the personalized ranking of British Universities. In Ref. [18], VIKOR was employed as the MCDM method in the ranking of universities in Turkey based on academic performance only. The authors in Ref. [19] presented the use of TOPSIS with Fuzzy type- 2 for managing the choice of a university. The service quality was based on SERVQUAL model, which is too general to handle the variations in the educational sector while ranking Higher Institutions [32, 33]. Ref. [15] proposed a fuzzy AHP for ranking the performances of $5 \mathrm{UK}$ universities with respect to 4 criteria. In Ref. [46], an AHP method was employed to determine the weight of each criterion and the PROMETHEE method was used in ranking the institutions using a web crawled data.

To the best of our knowledge, different MCDM methods have not been considered comparatively to show different rankings of alternatives to the decision-makers. Hence, this work reduces bias by using results from four fuzzy MCDM methods to ascertain the reliability of ranked alternatives in measuring service quality in higher institutions. Since MCDM methods combine their input data differently, they can therefore give an overall distinctive performance value for each alternative which can result in different rankings. This can be used as a benchmark for determining the reliability of the evaluation and ranking result [32]. In view of this, the ranking order and evaluation in this study was based on four Multi-Attribute Utility Theory (MAUT) methods: TOPSIS, Yager's Min-Max, Compensatory, and Ordered Weighted Averaging (OWA). FAHP algorithm using the iterative power method was proposed to obtain criteria weights that were defined in the extended multi-dimensional HiEdQUAL model. The fuzzy AHP alongside the four fuzzy MCDM methods were implemented with Java programming Language. This study was able to present the general importance of each service quality factor, reveal each institution's shortfalls and strong points quantitatively, and rank the institutions accordingly based on multiple criteria.

\section{Methodology}

In this work, the evaluation process is distinctly covered in four steps as shown in Figure 1, which are (i) definition and establishment of criteria to evaluate the higher institutions based on their quality of service; (ii) the determination of each criterion weight; (iii) determination of criteria performance for each alternative; and (iv) evaluation and ranking of alternatives. The alternatives considered for evaluation are 2 private universities and 2 public universities from the south-west region of Nigeria.

\subsection{Criteria Definition Based on Ext-HiEdQUAL Service} Model. In this study, HiEdQUAL service quality model, which is specific with respect to measurement of service quality in higher institutions, was adopted with few additional criteria. The regular HiEdQUAL model is based on five dimensional concepts, which are Teaching and Course content (TC), Administrative Services (AS), Academic Facilities (AF), Campus Infrastructure (CI), and Support Service (SS). Each dimensional concept has its attributes embedded such that they are weighted individually. To fully come to terms with expectations of the students in relation to QoS and the global relevance of Nigerian universities, another factor INTERNALISATION (IN) was introduced. This additional concept underlines the importance of improving excellence in higher institutions and attaining global relevance. The additional attributes/criteria, which make up IN that were considered include: (i) University provides international exchange programmes/collaboration; (ii) University has a number of international lecturers/faculty; (iii) University has standard collaborations for recruitment of international staff and students; and (iv) University has international students. These attributes can provide the focal point for rapid development of institution's products and values, acceleration of its goals, and global relevance among its contemporaries. However, these attributes were not sufficiently embedded in the regular HiEdQUAL model. Therefore, the Ext-HiEdQUAL service quality model proposed in this work produced six concepts and 33 criteria. Each of the criteria is rated based on the Fuzzy linguistic values (very dissatisfied, dissatisfied, fair, satisfied, and very satisfied). The Ext-HiEdQUAL QoS criteria model and its notations are shown in Table 1.

3.2. Fuzzy Set Theory. In order to handle the subjectivity in the assessment, three Fuzzy processes were incorporated into the MCDM methods for appropriate recommendations. These are: (i) Fuzzification process; (ii) Fuzzy Aggregation process; and (iii) Defuzzification.

3.2.1. The Fuzzification Process. This models the uncertainties and imprecision of the decision-makers involved in the evaluation process. The students are the decisionmakers, being the primary stakeholders of tertiary institutions. In order to elicit criteria importance and institution's performance with respect to the criteria, two linguistic variables are defined and fuzzified: the "Perceived Importance" and "Perceived Performance." These linguistic variables represent the judgments of the decision-makers for eliciting the perceived importance of one criterion over another and perceived performance of each alternative in relation to the Ext-HiEdQUAL QoS model.

In order to fuzzify the linguistic values of both linguistic variables, "perceived importance" and "perceived performance," a triangular membership function model is used because it is easy computationally, and suitable for the process. The linguistic variables and their corresponding triangular membership value for each linguistic value are shown in Tables 2 and 3. The membership function $\mu_{A}(x)$ of a Triangular Fuzzy Number (TFN) is defined in (1) and (2): 


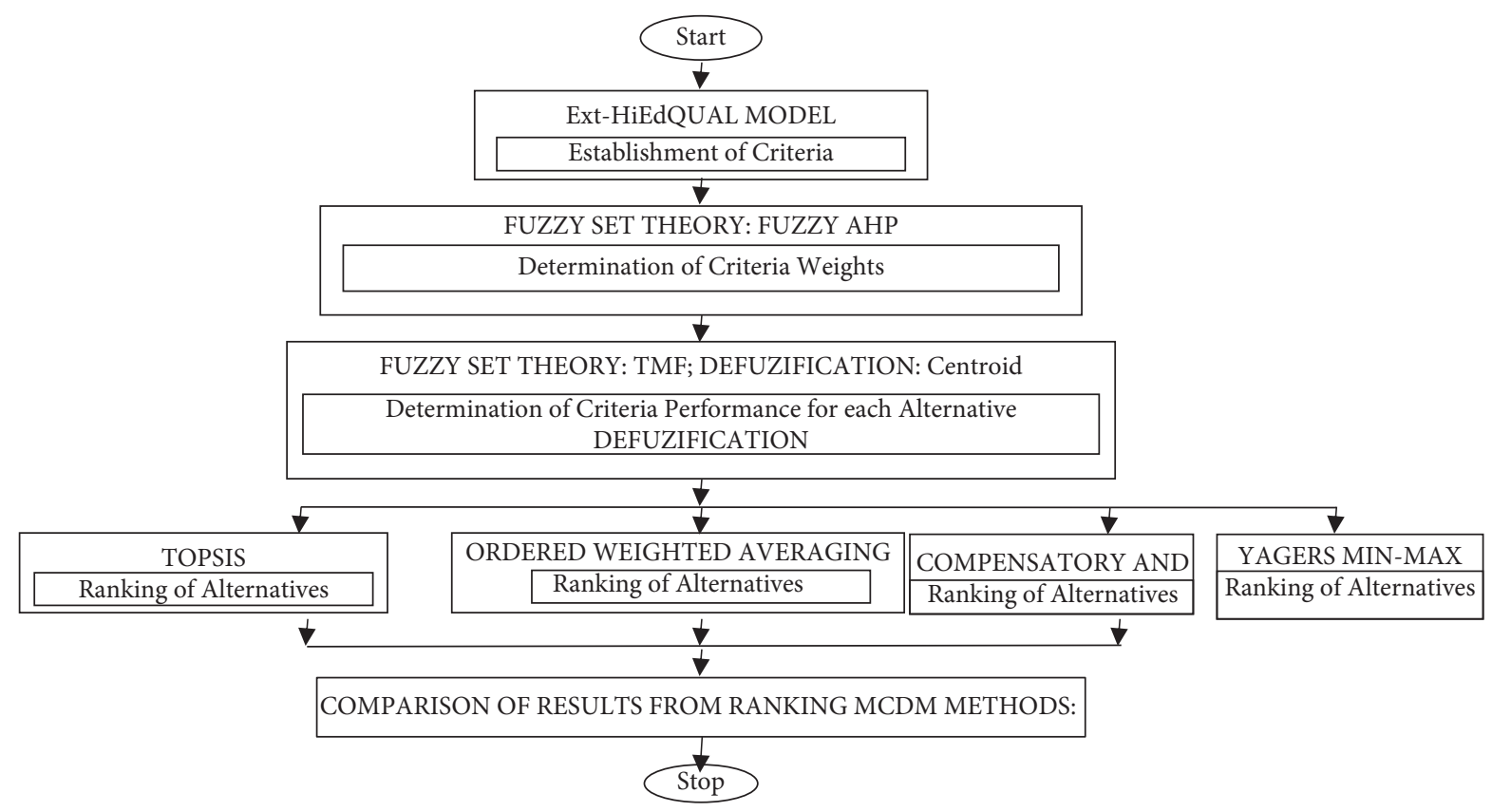

FIGURE 1: The tertiary institution service quality assessment workflow.

TABle 1: The Ext-HiEdQUAL criteria model with corresponding weights.

\begin{tabular}{|c|c|c|c|}
\hline S/no & Criteria code & Selected criteria & Weights \\
\hline 1. & TC1 & Teachers are responsive and accessible & 0.0256 \\
\hline 2. & TC2 & Teachers follow curriculum strictly & 0.0250 \\
\hline 3. & TC3 & Teachers follow good teaching practices & 0.0282 \\
\hline 4. & TC4 & Relevance between programme and syllabus & 0.0347 \\
\hline 5. & TC5 & Course content develops students' knowledge & 0.0427 \\
\hline 6. & TC6 & Department informs schedules, exams, results on time & 0.0388 \\
\hline 7. & TC7 & Teachers complete syllabus on time & 0.0284 \\
\hline 8. & TC8 & Department has sufficient academic staff & 0.0273 \\
\hline 9. & TC9 & University has more adjunct lecturers than in-house lecturers & 0.0306 \\
\hline 10 & TC10 & Departments reflect current trends in the curriculum & 0.0292 \\
\hline 11. & AS1 & Administrative staff provide service without delay & 0.0182 \\
\hline 12. & AS2 & Administrative staff are courteous and willing to help & 0.0262 \\
\hline 13. & AS3 & Administrative staff provide error-free work & 0.0270 \\
\hline 14. & AS4 & Administration maintains accurate storage and retrieval of records & 0.0312 \\
\hline 15. & AS5 & Administrative staff are accessible during office hours & 0.0350 \\
\hline 16. & AS6 & University has safety and security measures & 0.0159 \\
\hline 17. & AF1 & Departments have adequate teaching facilities & 0.0166 \\
\hline 18. & AF2 & Classrooms are equipped with teaching aids & 0.0278 \\
\hline 19. & AF3 & Department has sufficient class rooms & 0.0298 \\
\hline 20. & AF4 & University has adequate auditoriums, conference halls, etc. & 0.0312 \\
\hline 21. & AF5 & Library has adequate academic resources & 0.0361 \\
\hline 22. & AF6 & Computer labs have adequate equipment and internet facilities & 0.0161 \\
\hline 23. & CI1 & University has adequate hostel facilities & 0.0217 \\
\hline 24. & $\mathrm{CI} 2$ & University has adequate medical facilities (health centres) & 0.0438 \\
\hline 25. & $\mathrm{CI} 3$ & University has adequate social amenities (canteen, shopping centre, bank, ATM, post office, etc.) & 0.0518 \\
\hline 26. & $\mathrm{CI} 4$ & Campus infrastructure is well maintained. & 0.0206 \\
\hline 27. & SS1 & University has sufficient sports and recreation facilities. & 0.0314 \\
\hline 28. & SS2 & University/department provides placement services. & 0.0387 \\
\hline 29. & SS3 & University provides counselling services. & 0.0326 \\
\hline 30. & IN1 & University provides international exchange programmes /collaboration & 0.0341 \\
\hline 31. & IN2 & University has a number of international lecturers/faculty. & 0.0311 \\
\hline 32. & IN3 & University has standard collaborations for recruitment of international staff and students. & 0.0394 \\
\hline 33. & IN4 & University has international students. & 0.0334 \\
\hline
\end{tabular}


TABLE 2: Linguistic values for pairwise comparison of criteria importance (weights) for fuzzy AHP and their corresponding and reciprocal triangular fuzzy numbers.

\begin{tabular}{lcc}
\hline Linguistic values & Corresponding triangular fuzzy numbers & Reciprocal fuzzy number \\
\hline Equally important (EI) & $(0,0.1,0.3)$ & \\
Moderately important (M) & $(0.1,0.3,0.5)$ & $(1 / 0.5,1 / 0.3,1 / 0.1)$ \\
Strongly important (S) & $(0.3,0.5,0.7)$ & $(1 / 0.7,1 / 0.5,1 / 0.3)$ \\
Very strongly important (VS) & $(0.5,0.7,0.9)$ & $(1 / 0.9,1 / 0.7,1 / 0.5)$ \\
Extremely important(EX) & $(0.7,0.9,1.0)$ & $(1,1 / 9,1 / 0.7)$ \\
\hline
\end{tabular}

TABLE 3: Linguistic values for the qualitative measurement of perceived performance of alternatives and their corresponding triangular fuzzy numbers.

\begin{tabular}{lcc}
\hline Linguistic values & Corresponding triangular fuzzy numbers & Classification \\
\hline Very dissatisfied (VDS) & $(0,1,3)$ & 1 \\
Dissatisfied (DS) & $(1,3,5)$ & 2 \\
Fair (F) & $(3,5,7)$ & 3 \\
Satisfied (S) & $(5,7,9)$ & 4 \\
Very satisfied (VS) & $(7,9,10)$ & 5 \\
\hline
\end{tabular}

$$
\left(\mu_{x}\right) \text { Triangle }=\left\{\begin{array}{c}
0 \text { if } x \leq k \text { or } x>m \\
\frac{x-k}{l-k} \text { if } k<x \leq l \\
\frac{m-x}{m-l} \text { if } l<x \leq m
\end{array}\right\},
$$

where $k$ is lower boundary; $l$ is median point, and $m$ is upper boundary, $m \neq 1, u \neq m$, as depicted in Figure 2 such that $\mu_{A}(x): X \longrightarrow\{0,1\}$, where

$$
\begin{aligned}
\mu_{A}(x) & =1, \quad \text { if } x \text { is totally in } A ; \\
\mu_{A}(x) & =0, \quad \text { if } x \text { is not in } A ; \\
0 & <\mu_{A}(x)<1, \quad \text { if } x \text { is partially in } A .
\end{aligned}
$$

The linguistic values for the linguistic variable "Perceived Importance" for eliciting each criterion importance from decision-makers are identified as

Perceived Importance \{equally important (EI), moderately important (MI), strongly important (SI), very strongly important (VSI), and extremely important (EXI)\}

Each Fuzzy set is represented by the fuzzy graph in Figure 3. Also, the linguistic values for the linguistic variable "Perceived Performance" for eliciting the performance of each institution with respect to the QoS criteria is defined as:

Perceived Performance \{very dissatisfied (VDS), dissatisfied (DS), fair (F), satisfied (S), and very satisfied (VS)\}

Each fuzzy set is represented by the fuzzy graph in Figure 4.

3.2.2. The Fuzzy Aggregation Process. Based on the inherent subjectivity in the evaluation process, the perceptions of the decision-makers are aggregated using the arithmetic operations of Fuzzy set defined in (3). Fifty students in each of the four institutions were polled using a survey in relation to the Ext-HiEdQUAL model to determine the performance of the institutions, respectively. These perceptions are in two parts:

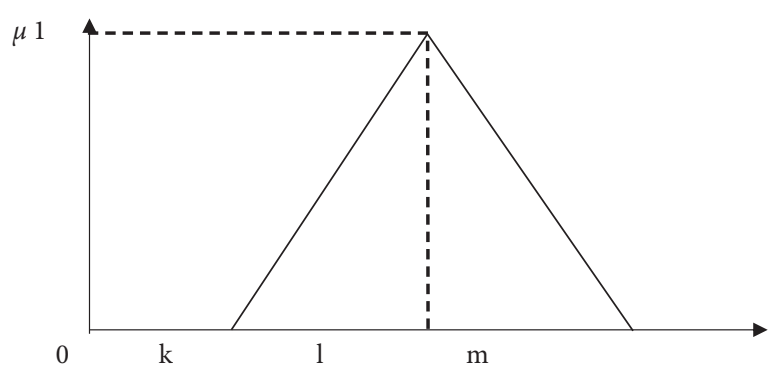

Figure 2: Triangular fuzzy number.

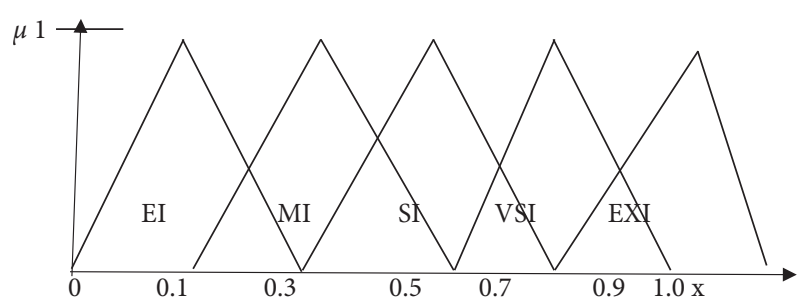

Figure 3: Fuzzy sets of the linguistic values for perceived importance.

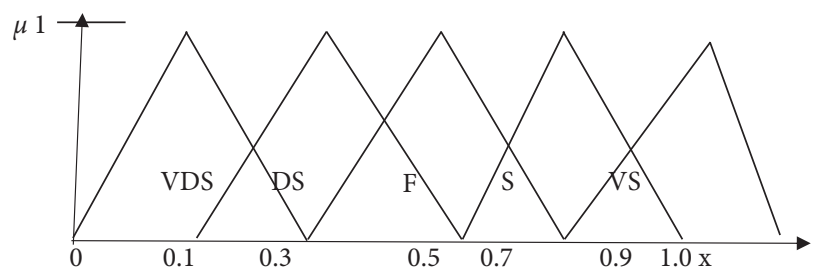

FIgURE 4: Fuzzy sets of the linguistic values for perceived performance.

first, the perceptions based on criteria importance (Perceived Importance) and second, on alternative performance with respect to the Ext-HiEdQUAL criteria Model (Perceived Performance). Consequently, these perceptions 
modelled as fuzzy variables are averaged using the following formula in (4), which is expounded in Refs. [47, 48]:

$$
A_{\mathrm{ave}}=\frac{1}{n}\left(\sum_{i=1}^{n} k_{i} \sum_{i=1}^{n} l_{i} \sum_{i=1}^{n} m_{i}\right) .
$$

Its average triangular fuzzy number will now be:

$$
A_{\mathrm{ave}}=\left(k_{a}, l_{a}, m_{a}\right)=\left(\frac{1}{n} \sum_{i=1}^{n} k_{i}, \frac{1}{n} \sum_{i=1}^{n} l_{i}, \frac{1}{n} \sum_{i=1}^{n} m_{i}\right) .
$$

Equation (4) gives us an average fuzzy quantitative performance value for each criterion with respect to the decision-makers' assessment. The Fuzzy performance for each Higher Institution (HI) with respect to the criteria is shown in Table 4.

3.2.3. Defuzzification. According to Ref. [49], excessive fuzzification does not infer better modeling of reality, and this could end up being counterproductive. There is a need to transform the fuzzy nature of both the average performance values of each criterion and the criteria importance values into best nonfuzzy value since final judgments are best when crisp in nature. Therefore, in order to transform it into its best nonfuzzy performance (BNF) value, the centroid defuzzification method was employed in this study because it is monotonous, consistent, and its deterministic response curve is characterized by a smooth and continuous behavior [50]. The deffuzified value of a fuzzy number can be attained with equation (5). The best nonfuzzy performance values using centroid defuzzification with respect to selected criteria are shown in Table 5 and graphically represented in Figures 5-8.

$$
\mathrm{BNP}=\frac{(m-k)+(l-k)}{3}+k
$$

\subsection{Fuzzy Analytical Hierarchy Process (AHP). AHP was} proposed by Saaty [51], and is one of the most commonly utilized weighting MCDM methods [35]. The fusion of Fuzzy set concept addresses the weakness of the AHP by capturing the uncertainties of the decision-makers before making recommendations on criteria importance. Fuzzy AHP was adopted as a weighting model for determining each criterion weight. The experts considered in this study for the rating of each criterion as relevant to higher institution are people in the University Quality Assurance Unit, Academic Planning Unit, and Heads of Departments from the universities that were considered due to their deeper knowledge about their university's quality of service. The experts are considered for the rating of the criteria importance based on the fuzzy linguistic values \{Equally important, moderately more important, strongly more important, very strongly more important, and extremely more important\}. For the determination of weights/priorities, various methods of AHP have been adopted [52]. Eigenvector method, using the iterative Power method [52], was employed in this study and implemented in Java Programming language. The Fuzzy AHP algorithm is stated as:

Step 1: Construct a fuzzy pairwise comparison matrix for each decision-maker (DM) with the aid of the linguistic scale in Table 2. Each element, $\left(\widetilde{a}_{i j}\right)$ in the pairwise comparison matrix, $\widetilde{A}$ is a fuzzy number corresponding to its linguistic value selected by the decision-maker (DM) in Table 2.

Consequently, the relative importance of one criterion over another can be subjectively expressed by a DM in constructing the pairwise comparison matrix using the following steps:

(i) If two criteria have equal importance in pairwise comparison, enter corresponding fuzzy number in Table 2 for both criteria;

(ii) If one of them is moderately more important than the other, enter the corresponding fuzzy number and for the other enter reciprocal fuzzy number in Table 2;

(iii) If one of them is strongly more important than the other, enter the corresponding fuzzy number and for the other enter reciprocal fuzzy number in Table 2;

(iv) If one of them is very strongly more important than the other, enter the corresponding fuzzy number and for the other enter reciprocal fuzzy number in Table 2;

(v) If one of them is extremely important than the other, enter the corresponding fuzzy number, and for the other enter reciprocal fuzzy number in Table 2;

Then, we have:

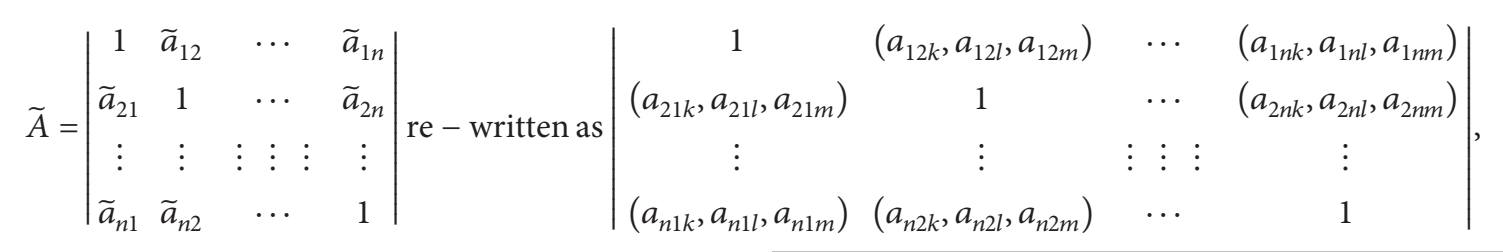

where $\left(a_{12 k}, a_{12 l}, a_{12 m}\right)$ is represented as a triangular fuzzy number for comparison criterion $i$ and $j$; $\left(a_{21 k}\right.$, $\left.a_{21}, a_{21 m}\right)$ represents the reciprocal fuzzy number for the comparison between criterion $j$ and $i$. 
TABLE 4: Fuzzy performance for each higher institution (HI) with respect to the criteria. A, B, C, D represent the four universities under consideration.

\begin{tabular}{|c|c|c|c|c|}
\hline \multirow{2}{*}{ Criteria } & \multicolumn{4}{|c|}{ Fuzzy criteria performance of the higher institutions (HI) (fuzzification) } \\
\hline & HI A & HI B & $\mathrm{HI} \mathrm{C}$ & HI D \\
\hline TC1 & $(3.600,5.480,7.400)$ & $(5.040,7.040,8.680)$ & $(4.580,6.560,8.380)$ & $(4.600,6.600,8.480)$ \\
\hline TC2 & $(4.120,6.120,8.020)$ & $(5.240,7.240,8.900)$ & $(4.660,6.640,8.480)$ & $(4.200,6.200,8.140)$ \\
\hline TC3 & $(3.640,5.560,7.460)$ & $(4.740,6.720,8.500)$ & $(3.920,5.920,7.860)$ & $(4.040,6.040,7.980)$ \\
\hline TC4 & $(3.800,5.720,7.640)$ & $(4.580,6.520,8.360)$ & $(3.740,5.720,7.620)$ & $(4.560,6.560,8.420)$ \\
\hline TC5 & $(3.820,5.720,7.580)$ & $(5.040,7.000,8.760)$ & $(4.460,6.440,8.280)$ & $(4.680,6.680,8.540)$ \\
\hline TC6 & $(4.240,6.160,7.980)$ & $(5.240,7.240,8.800)$ & $(3.540,5.480,7.380)$ & $(3.760,5.760,7.720)$ \\
\hline TC7 & $(3.800,5.800,7.740)$ & $(4.620,6.600,8.320)$ & $(2.820,4.720,6.700)$ & $(3.360,5.360,7.340)$ \\
\hline TC8 & $(3.600,5.520,7.460)$ & $(4.780,6.720,8.420)$ & $(3.460,5.400,7.300)$ & $(4.440,6.440,8.360)$ \\
\hline TC9 & $(3.240,5.160,7.120)$ & $(3.540,5.440,7.320)$ & $(3.140,5.080,7.000)$ & $(2.780,4.760,6.720)$ \\
\hline TC10 & $(3.140,5.040,7.040)$ & $(4.560,6.520,8.280)$ & $(3.420,5.360,7.320)$ & $(3.800,5.800,7.780)$ \\
\hline AS1 & $(2.880,4.760,6.720)$ & $(3.900,5.840,7.800)$ & $(2.720,4.640,6.580)$ & $(2.940,4.880,6.840)$ \\
\hline AS2 & $(3.600,5.520,7.460)$ & $(4.240,6.200,8.040)$ & $(3.040,5.000,6.940)$ & $(3.340,5.240,7.220)$ \\
\hline AS3 & $(3.240,5.120,7.060)$ & $(3.600,5.560,7.420)$ & $(3.040,5.040,7.020)$ & $(3.280,5.240,7.200)$ \\
\hline AS4 & $(3.820,5.720,7.600)$ & $(3.920,5.880,7.780)$ & $(3.900,5.840,7.780)$ & $(3.600,5.600,7.560)$ \\
\hline AS5 & $(3.840,5.760,7.600)$ & $(4.240,6.200,8.060)$ & $(4.040,6.040,7.940)$ & $(4.400,6.400,8.300)$ \\
\hline AS6 & $(3.340,5.160,7.100)$ & $(5.060,7.040,8.660)$ & $(4.240,6.240,8.060)$ & $(3.620,5.600,7.560)$ \\
\hline AF1 & $(2.620,4.400,6.340)$ & $(4.040,6.000,7.840)$ & $(2.620,4.480,6.400)$ & $(3.360,5.280,7.220)$ \\
\hline AF2 & $(2.340,4.120,6.100)$ & $(4.760,6.760,8.500)$ & $(2.540,4.440,6.360)$ & $(3.600,5.560,7.500)$ \\
\hline AF3 & $(3.420,5.360,7.340)$ & $(4.160,6.080,7.860)$ & $(2.880,4.720,6.680)$ & $(4.360,6.320,8.200)$ \\
\hline AF4 & $(3.040,4.920,6.840)$ & $(4.860,6.840,8.520)$ & $(3.480,5.400,7.280)$ & $(4.020,5.960,7.860)$ \\
\hline AF5 & $(4.120,6.120,7.940)$ & $(5.640,7.640,9.160)$ & $(3.820,5.800,7.600)$ & $(3.940,5.920,7.800)$ \\
\hline AF6 & $(2.640,4.440,6.400)$ & $(4.820,6.760,8.420)$ & $(3.020,4.840,6.740)$ & $(2.780,4.680,6.640)$ \\
\hline $\mathrm{C} 11$ & $(2.140,3.880,5.860)$ & $(4.600,6.560,8.300)$ & $(2.760,4.640,6.620)$ & $(1.140,2.600,4.580)$ \\
\hline $\mathrm{C} 12$ & $(2.540,4.320,6.300)$ & $(4.680,6.640,8.360)$ & $(3.100,5.040,6.940)$ & $(3.080,5.040,7.000)$ \\
\hline $\mathrm{C} 13$ & $(2.920,4.760,6.720)$ & $(4.580,6.520,8.240)$ & $(2.660,4.560,6.500)$ & $(4.320,6.320,8.240)$ \\
\hline C14 & $(2.380,4.120,6.100)$ & $(4.080,6.040,7.920)$ & $(3.620,5.560,7.440)$ & $(2.760,4.720,6.680)$ \\
\hline SS1 & $(3.000,4.840,6.780)$ & $(4.060,6.000,7.820)$ & $(3.340,5.280,7.200)$ & $(3.740,5.720,7.620)$ \\
\hline SS2 & $(2.640,4.440,6.420)$ & $(3.200,5.120,7.000)$ & $(3.040,4.920,6.860)$ & $(2.800,4.720,6.700)$ \\
\hline SS3 & $(2.240,4.000,6.000)$ & $(4.340,6.280,8.060)$ & $(3.780,5.720,7.540)$ & $(3.580,5.520,7.480)$ \\
\hline IN1 & $(2.180,3.880,5.880)$ & $(4.400,6.360,8.200)$ & $(3.040,4.960,6.920)$ & $(2.580,4.440,6.420)$ \\
\hline IN2 & $(1.285,2.836,4.836)$ & $(3.560,5.520,7.380)$ & $(2.220,4.000,5.980)$ & $(2.100,3.920,5.900)$ \\
\hline IN3 & $(1.775,3.571,5.571)$ & $(3.880,5.800,7.680)$ & $(2.380,4.160,6.140)$ & $(2.320,4.240,6.220)$ \\
\hline IN4 & $(1.632,3.285,5.285)$ & $(3.600,5.520,7.340)$ & $(2.260,4.080,6.040)$ & $(2.280,4.160,6.100)$ \\
\hline
\end{tabular}

Step 2: Add the fuzzy numbers selected by each DM for each pairwise comparison of ${ }_{i}$ th and ${ }_{j}$ th criterion using equation (3) if there is more than one DM, and collapse into an aggregated one using equation (4).

Step 3: Due to the condition required of linear additive models like AHP as certainty is prerequisite before final results, defuzzify averaged fuzzy numbers from step (2) for each $\left(a_{1 n k}, a_{1 n l}, a_{1 n m}\right)$ in $\tilde{A}$ using the centroid defuzzification formula in equation (5).

Step 4: Square the averaged pairwise comparison matrix: $\mathbf{A}_{n+1}=\mathbf{A}_{n} * \mathbf{A}_{n}$.

Step 5: Perform the row sums that are calculated and normalized using equations (7) and (8), respectively:

$$
r i=\sum_{i} a i j
$$

where $r i$ is the summation of the row values and

$$
p i=\frac{r i}{\sum_{i} r i}
$$

where $p i$ is the normalization of the sums.

This produces the first eigenvector.

Step 6: Repeat steps 4 and 5 using the new matrix $A_{n+2}$ derived from squaring the $A_{n}$

Step 7: Stop when there is a difference between the current and last eigenvector solution in two consecutive priorities calculations derived from steps 5 and 6 .

The determined weight for each criterion is shown in Table 1 and is graphically represented in Figure 9.

3.4. Ranking of Alternatives Using MCDM Methods. For the ranking of the tertiary institutions of learning under consideration, four MCDM compensatory (MAUT) methods were applied for the evaluation to rank the tertiary institutions. These are: TOPSIS, Yager's min-max, Compensatory AND, and OWA.

3.4.1. TOPSIS. TOPSIS, proposed by Hwang and Yoon [53], was developed based on the ideal that the best alternative should have the shortest distance to the positive ideal situation and the 
TABLe 5: Best non-fuzzy performance for each higher institution (HI) with respect to the criteria.

\begin{tabular}{|c|c|c|c|c|c|}
\hline \multirow[t]{2}{*}{ Criteria } & \multirow[t]{2}{*}{ Selected criteria } & \multicolumn{4}{|c|}{$\begin{array}{l}\text { Best non-fuzzy performance of } \\
\text { the higher institutions (HI) } \\
\text { (centroid defuzzification) }\end{array}$} \\
\hline & & HI A & HI B & $\mathrm{HI} \mathrm{C}$ & HI D \\
\hline TC1 & Teachers are responsive and accessible & 5.4933 & 4.7867 & 6.5067 & 6.5600 \\
\hline TC2 & Teachers follow curriculum strictly & 6.0867 & 5.5267 & 6.5933 & 6.1800 \\
\hline TC3 & Teachers follow good teaching practices & 5.5533 & 5.1400 & 5.9000 & 6.0200 \\
\hline TC4 & Relevance between programme and syllabus & 5.7200 & 5.7133 & 5.6933 & 6.5133 \\
\hline TC5 & Course content develops students' knowledge & 5.7067 & 5.7333 & 6.3933 & 6.6333 \\
\hline TC6 & Department informs schedules, exams, results on time & 6.1267 & 5.2000 & 5.4667 & 5.7467 \\
\hline TC7 & Teachers complete syllabus on time & 5.7800 & 4.4533 & 4.7467 & 5.3533 \\
\hline TC8 & Department has sufficient academic staff & 5.5267 & 4.1867 & 5.3867 & 6.4133 \\
\hline TC9 & University has more adjunct lecturers than in-house lecturers & 5.1733 & 5.3733 & 5.0733 & 4.7533 \\
\hline TC10 & Departments reflect current trends in the curriculum & 5.0733 & 4.9333 & 5.3667 & 5.7933 \\
\hline AS1 & Administrative staff provide service without delay & 4.7867 & 6.0600 & 4.6467 & 4.8867 \\
\hline AS2 & Administrative staff are courteous and willing to help & 5.5267 & 4.4933 & 4.9933 & 5.2667 \\
\hline AS3 & Administrative staff provide error-free work & 5.1400 & 3.9600 & 5.0333 & 5.2400 \\
\hline AS4 & Administration maintains accurate storage and retrieval of records & 5.7133 & 4.3867 & 5.8400 & 5.5867 \\
\hline AS5 & Administrative staff are accessible during office hours & 5.7333 & 4.8000 & 6.0067 & 6.3667 \\
\hline AS6 & University has safety and security measures & 5.2000 & 4.2000 & 6.1800 & 5.5933 \\
\hline AF1 & Departments have adequate teaching facilities & 4.4533 & 4.8733 & 4.5000 & 5.2867 \\
\hline AF2 & Classrooms are equipped with teaching aids & 4.1867 & 4.5000 & 4.4467 & 5.5533 \\
\hline AF3 & Department has sufficient classrooms & 5.3733 & 4.0800 & 4.7600 & 6.2933 \\
\hline AF4 & University has adequate auditoriums, conference halls, etc. & 4.9333 & 3.9800 & 5.3867 & 5.9467 \\
\hline AF5 & Library has adequate academic resources & 6.0600 & 2.9533 & 5.7400 & 5.8867 \\
\hline AF6 & Computer labs have adequate equipment and internet facilities & 4.4933 & 3.5933 & 4.8667 & 4.7000 \\
\hline $\mathrm{C} 11$ & University has adequate hostel facilities & 3.9600 & 3.3600 & 4.6733 & 2.7733 \\
\hline $\mathrm{C} 12$ & University has adequate medical facilities (Health centres) & 4.3867 & 4.7867 & 5.0267 & 5.0400 \\
\hline $\mathrm{C} 13$ & $\begin{array}{l}\text { University has adequate social amenities (Canteen, Shopping centre, Bank, ATM, Post office, } \\
\text { etc.) }\end{array}$ & 4.8000 & 5.5267 & 4.5733 & 6.2933 \\
\hline $\mathrm{C} 14$ & Campus infrastructure is well maintained. & 4.2000 & 5.1400 & 5.5400 & 4.7200 \\
\hline SS1 & University has sufficient sports and recreation facilities. & 4.8733 & 5.7133 & 5.2733 & 5.6933 \\
\hline SS2 & University/Department provides placement services. & 4.5000 & 5.7333 & 4.9400 & 4.7400 \\
\hline SS3 & University provides counselling services & 4.0800 & 5.2000 & 5.6800 & 5.5267 \\
\hline IN1 & University provides international exchange programmes/collaboration & 3.9800 & 4.4533 & 4.9733 & 4.4800 \\
\hline IN2 & University has a number of international lecturers/faculty. & 2.9533 & 4.1867 & 4.0667 & 3.9733 \\
\hline IN3 & University has standard collaborations for recruitment of international staff and students. & 3.5933 & 5.3733 & 4.2267 & 4.2600 \\
\hline IN4 & University has international students. & 3.3600 & 4.9333 & 4.1267 & 4.1800 \\
\hline
\end{tabular}

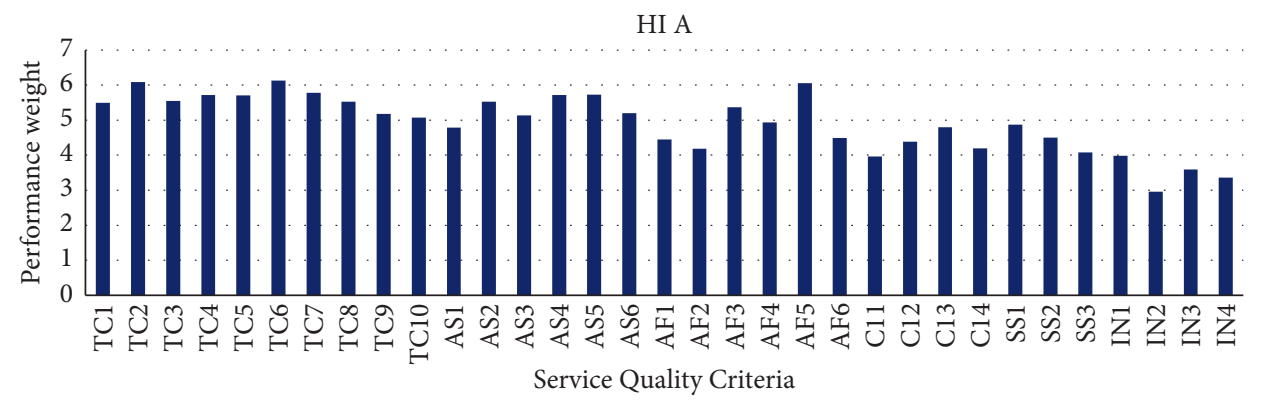

FIGURE 5: Higher institution "A" performance against each criterion.

farthest to the negative ideal situation. The best alternative to the least is selected by using the following steps, which was implemented in Java programming language:

Step 1: Calculation of the normalized performance matrix

$$
r_{i j}=\frac{a_{i j}}{\sqrt{\sum_{m}^{i=1} a_{i j}^{2}}}, \quad i=1,2, \ldots, m j=1,2, \ldots n
$$

where $a_{i j}$ is the performance matrix, $i$ is the alternative number, and $j$ is the criterion number 
HI B

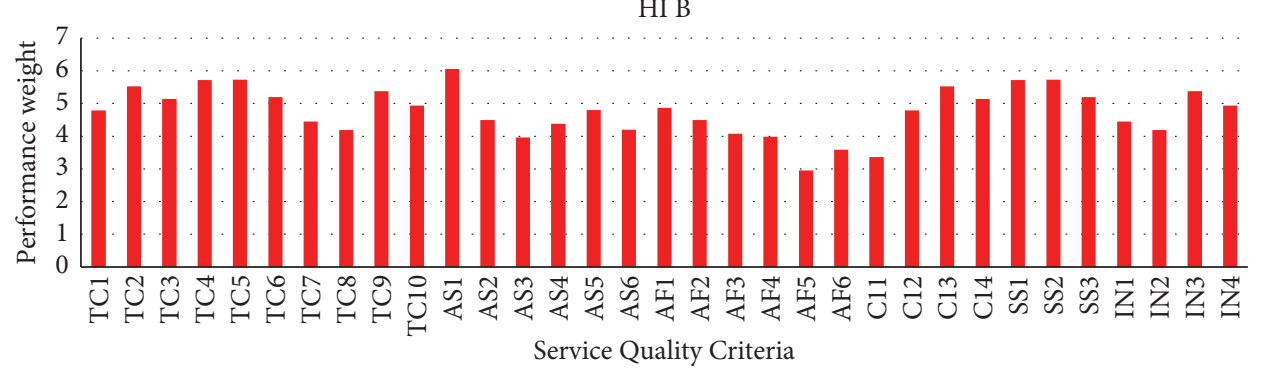

FIGURE 6: Higher institution "B" performance against each criterion.

HI C

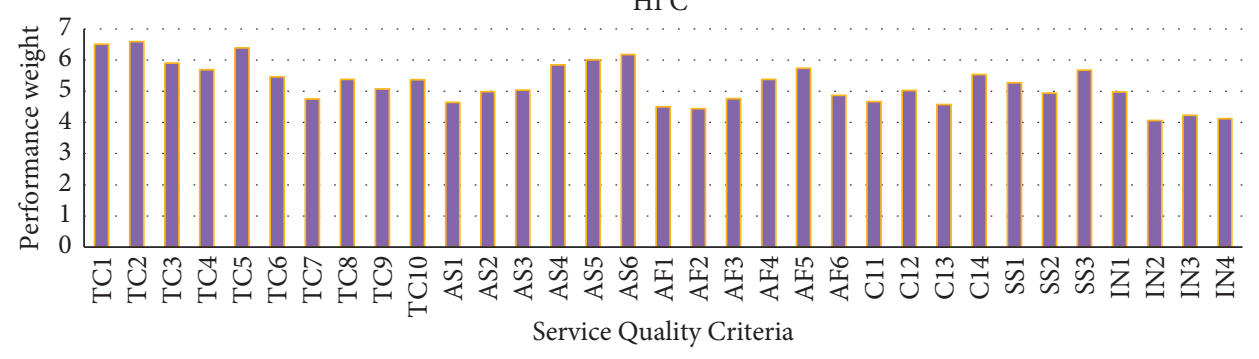

FIGURE 7: Higher institution “C” performance against each criterion.

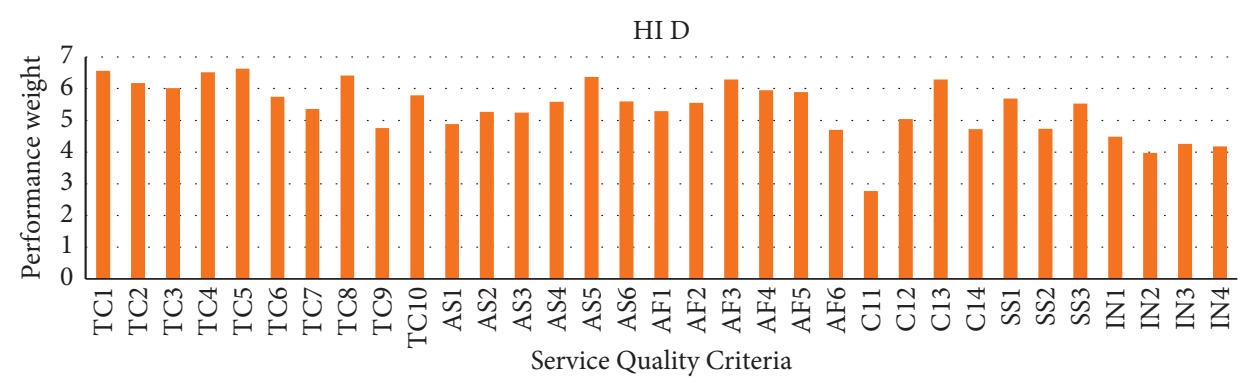

FIGURE 8: Higher institution “D” performance against each criterion.

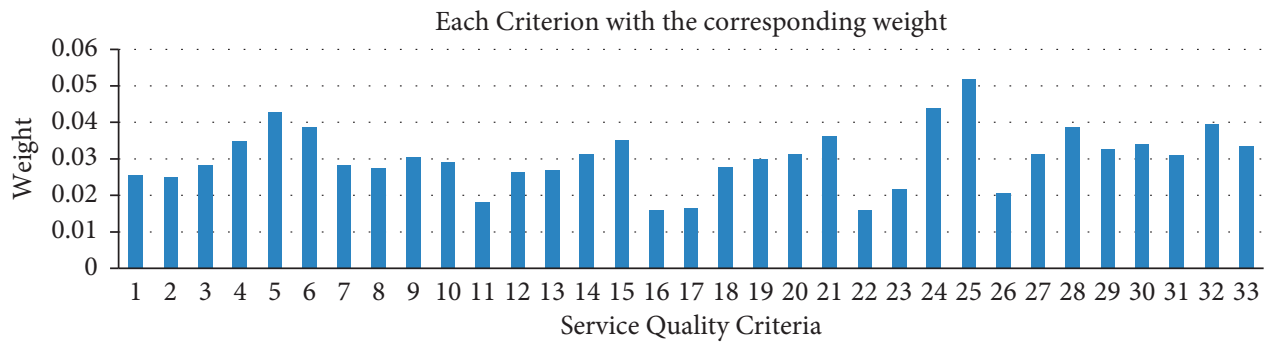

FIGURE 9: Graphical representation of the fuzzy AHP derived weights of Ext- HiEDQUAL QoS criteria.

Step 2: Calculation of weighted and normalized performance matrix

$$
v_{i j}=w_{j} \times r_{i j}, \quad i=1,2, \ldots, m j=1,2, \ldots, n,
$$

where $w_{j}$ is the weight of criterion $j$.

Step 3: Determination of positive ideal solution and negative ideal solution
The weighted and normalized values in matrix $V_{i j}$ give rise to the positive ideal solution $\left(A^{+}\right)$and negative ideal solution $\left(A^{-}\right)$

$$
\begin{aligned}
& A^{+}=\left(V_{1}^{+}, V_{2}^{+}, \ldots, V_{n}^{+}\right), \\
& A^{-}=\left(V_{1}^{-}, V_{2}^{-}, \ldots, V_{n}^{-}\right),
\end{aligned}
$$


where $V_{j}^{+}$is the best alternative value in criterion $j$ from the $V_{i j}$ matrix, $V_{j}^{-}$is the worst alternative value in criterion $j$ from the $V_{i j}$ matrix.

Step 4: Calculation of distance values between alternatives

The distance of alternatives from the positive ideal solution $\mathrm{Si}^{+}$and the distance of alternatives from the negative ideal solution $\mathrm{Si}^{-}$are calculated with (12) and (13), respectively.

$$
\begin{aligned}
& S_{i}^{+}=\sqrt{\sum_{j=1}^{n}\left(V_{i j}-V_{j}^{+}\right)^{2}}, \quad i=1,2, \ldots, m, \\
& S_{i}^{-}=\sqrt{\sum_{j=1}^{n}\left(V_{i j}-V_{j}^{-}\right)^{2}}, \quad i=1,2, \ldots, m .
\end{aligned}
$$

Step 5: Calculation of the closeness to the positive-ideal solution

$$
C_{i}^{+}=\frac{S_{i}^{-}}{S_{i}^{+}+S_{i}^{-}}, \quad i=1,2, \ldots, m
$$

$C_{i}^{+}$value is in the $0 \leq C_{i}^{+} \leq 1$ interval. As $C_{i}^{+}$gets closer to 1 , alternative $i$ gets closer to $A^{+}$, whereas if $C_{i}^{+}$gets closer to 0 , alternative $i$ gets closer to $A^{-}$. The result is shown in Table 6.

Step 6: Arrangement of alternative choices: Alternatives are arranged according to the decreasing order of $C_{i}^{+}$.

Normalized Performance matrix and Weighted Normalized Performance matrix for each Higher Institution (HI) with respect to the criteria is shown in Table 6. The final ranking of the institutions performance with TOPSIS is shown in Table 7.

3.4.2. Compensatory AND Operator. The compensatory AND operator defined by Ref. [54] sought to emulate human's aggregation procedure in decision-making based on the t-norm and t-conorms on a unit interval. It is defined as:

$$
\mu_{A \theta B}=\mu_{A \cap B}^{1-\gamma} \cdot \mu_{A \cup B}^{\gamma},
$$

where $\theta$ is the Compensatory AND operator and $A$ and $B$ are the fuzzy sets. The membership of an object in the set $A \theta B$ equals the product of the weighted membership values for the intersection and the union.

If the intersection and the union are algebraically represented by the product and the algebraic sum, respectively, to represent a closer representation of human aggregation procedures, then (15) becomes:

$$
\mu_{\theta}=\left(\prod_{i=1}^{m} \mu_{i}\right)^{1-\gamma} *\left(1-\prod_{i=1}^{m}\left(1-\mu_{i}\right)\right)^{\gamma}, \quad 0 \leq \mu \leq 1 ; 0 \leq \gamma \leq 1 .
$$

If it is desired to introduce different weights for the sets in question, $\mu_{i}$ and $1-\mu_{i}$ could for instance be replaced by $\mu_{i}=\left(\vartheta_{i} / n\right)^{9 i}$ and $1-\mu_{i}=\left(1-\left(\vartheta_{i} / n\right)\right)^{9 i}$.

where $\vartheta_{i}$ are the (raw) membership values, $n$ is the highest possible defuzzified value, such that $n=10$ and $\delta_{i}$, their corresponding weights; and $\gamma=0.6$, which indicates the degree of compensation [54]. The sum of weights $\delta_{i}$ should be equal to the number of sets connected. That means $\sum_{i} \delta i=m[54]$.

This procedure was implemented in Java programming language and the final ranking value for each alternative using Compensatory AND is shown in Table 7 and Figure 10.

3.4.3. Yager's Min-Max. Yager's min-max has been reported as an efficient group decision-making technique [55]. The best alternative to least is selected by the following:

Let $X=\left\{x_{1}, x_{2}, \ldots, x_{n}\right\}$ be the set of Higher Institutions. Criteria are shown with $G_{j}$ fuzzy sets $j=1, \ldots, m$. The criterion importance is expressed by $w_{j}$. The attainment of criterion $G_{j}$ by Higher Institution $x_{\mathrm{i}}$ is expressed by the degree of membership $G_{j}\left(x_{i}\right)$.

In relation to [56], the decision is the intersection of all fuzzy criteria raised to the powers $w_{j}$ and is given as follows:

$$
\widetilde{D}=\widetilde{G}_{1}^{w_{1}} \cap \widetilde{G}_{2}^{w_{2}} \cap \cdots \cap \widetilde{G}_{m}^{w_{m}},
$$

where $w_{j}(j=1, \ldots, m)$ is the weight attached to the criterion $G_{j}(j=1, \ldots, m)$ depending on its importance. The defuzzified values in Table 5 for each higher institution, $x_{\mathrm{i}}$, could represent the criteria values, $G_{j}\left(x_{i}\right)[26,35]$ and the most optimal Higher Institution is one with the highest $\left(\mu_{G_{j}}\left(x_{i}\right)\right)$ in $\widetilde{D}$ [55]. The more the weight, $w_{j}$ is attached to criterion $\widetilde{G}_{j}$ exponentially, the more it is included in $\widetilde{D}$ as shown in (18).

$$
\left(\widetilde{D}=\left\{x_{i}^{\min }{ }_{j}\left(\mu_{G_{j}}\left(x_{i}\right)\right)^{w_{j}}, \quad \mid i=1, \ldots, n ; j=1, \ldots, m\right\}\right),
$$

$w_{j}$ represents the weight of each criterion computed by the AHP method. For this, $\sum_{j} w_{j}=m$, where $m$ is the total number of criteria [56]. The Yager's weighted criteria values, $\widetilde{G}_{m}^{w_{m}}$ for each higher institution, xi is depicted in Table 8 and the final ranking values, $\widetilde{D}$ for each alternative is shown in Table 7 and Figure 10.

3.4.4. Ordered Weighted Averaging (OWA). Ordered Weighted Averaging (OWA) was proposed by Yager and this is defined as cited in Ref. [4]:

"Definition: A mapping $F$ from.

(i) $I^{n} \longrightarrow I$ where $(I=[0,1])$ is called an OWA operator of dimension $n$ if associated with $\mathrm{F}$, which has a weighting vector $\mathbf{W}$

$$
W=\left(\begin{array}{l}
w_{1} \\
w_{2} \\
w_{n}
\end{array}\right) .
$$


TABLE 6: Normalized performance matrix and weighted normalized performance matrix.

\begin{tabular}{|c|c|c|c|c|c|c|c|c|c|c|}
\hline \multirow{2}{*}{ Selected criteria } & \multicolumn{4}{|c|}{ Normalized matrix performance } & \multicolumn{4}{|c|}{ Weighted normalized performance matrix } & \multirow{2}{*}{$A^{+}$} & \multirow{2}{*}{$A^{-}$} \\
\hline & HI A & HI B & HI C & HI D & HI A & HI B & HI C & HI D & & \\
\hline TC1 & 0.4297 & 0.5413 & 0.5090 & 0.5131 & 0.0110 & 0.0138 & 0.0130 & 0.0131 & 0.0138 & 0.0110 \\
\hline TC2 & 0.4675 & 0.5474 & 0.5064 & 0.4747 & 0.0117 & 0.0137 & 0.0126 & 0.0119 & 0.0137 & 0.0117 \\
\hline TC3 & 0.4594 & 0.5503 & 0.488 & 0.498 & 0.0130 & 0.0155 & 0.0138 & 0.0141 & 0.0155 & 0.0130 \\
\hline TC4 & 0.4676 & 0.5303 & 0.4654 & 0.5325 & 0.0162 & 0.0184 & 0.0162 & 0.0185 & 0.0185 & 0.0162 \\
\hline TC5 & 0.4436 & 0.5389 & 0.4969 & 0.5156 & 0.0189 & 0.0230 & 0.0212 & 0.0220 & 0.0230 & 0.0189 \\
\hline TC6 & 0.4990 & 0.5777 & 0.4452 & 0.4680 & 0.0193 & 0.0224 & 0.0173 & 0.0181 & 0.0224 & 0.0173 \\
\hline TC7 & 0.5128 & 0.5779 & 0.4212 & 0.4750 & 0.0146 & 0.0164 & 0.0120 & 0.0135 & 0.0120 & 0.0135 \\
\hline TC8 & 0.4593 & 0.5518 & 0.4477 & 0.5330 & 0.0125 & 0.0151 & 0.0122 & 0.0146 & 0.0151 & 0.0122 \\
\hline TC9 & 0.5058 & 0.5312 & 0.4960 & 0.4647 & 0.0155 & 0.0162 & 0.0152 & 0.0142 & 0.0162 & 0.0142 \\
\hline TC10 & 0.4454 & 0.5665 & 0.4711 & 0.5086 & 0.0130 & 0.0165 & 0.0138 & 0.0148 & 0.0165 & 0.0130 \\
\hline AS1 & 0.4726 & 0.5773 & 0.4588 & 0.4825 & 0.0086 & 0.0105 & 0.0083 & 0.0088 & 0.0105 & 0.0083 \\
\hline AS2 & 0.5021 & 0.5596 & 0.4536 & 0.4785 & 0.0131 & 0.0146 & 0.0119 & 0.0125 & 0.0146 & 0.0119 \\
\hline AS3 & 0.4906 & 0.5275 & 0.4804 & 0.5002 & 0.0133 & 0.0143 & 0.0130 & 0.0135 & 0.0143 & 0.0130 \\
\hline AS4 & 0.4967 & 0.5095 & 0.5077 & 0.4857 & 0.0155 & 0.0159 & 0.0158 & 0.0151 & 0.0159 & 0.0151 \\
\hline AS5 & 0.4721 & 0.5077 & 0.4946 & 0.5242 & 0.0165 & 0.0178 & 0.0173 & 0.0183 & 0.0183 & 0.0165 \\
\hline AS6 & 0.4327 & 0.5759 & 0.5143 & 0.4655 & 0.0069 & 0.0091 & 0.0082 & 0.0074 & 0.0091 & 0.0069 \\
\hline $\mathrm{AF} 1$ & 0.4376 & 0.5857 & 0.4422 & 0.5195 & 0.0073 & 0.0097 & 0.0074 & 0.0086 & 0.0097 & 0.0073 \\
\hline AF2 & 0.3944 & 0.6287 & 0.4189 & 0.5232 & 0.0110 & 0.0175 & 0.0116 & 0.0145 & 0.0175 & 0.0110 \\
\hline AF3 & 0.4758 & 0.5342 & 0.4215 & 0.5573 & 0.0142 & 0.0159 & 0.0126 & 0.0166 & 0.0166 & 0.0126 \\
\hline AF4 & 0.4259 & 0.5819 & 0.4651 & 0.5134 & 0.0133 & 0.0181 & 0.0145 & 0.0160 & 0.0181 & 0.0133 \\
\hline AF5 & 0.4787 & 0.5908 & 0.4534 & 0.4650 & 0.0173 & 0.0213 & 0.0164 & 0.0168 & 0.0213 & 0.0164 \\
\hline AF6 & 0.4276 & 0.6345 & 0.4632 & 0.4473 & 0.0069 & 0.0102 & 0.0075 & 0.0072 & 0.0102 & 0.0069 \\
\hline $\mathrm{C} 11$ & 0.4239 & 0.6943 & 0.5002 & 0.2968 & 0.0092 & 0.0151 & 0.0109 & 0.0064 & 0.0151 & 0.0064 \\
\hline $\mathrm{C} 12$ & 0.4128 & 0.6173 & 0.473 & 0.4742 & 0.0181 & 0.0270 & 0.0207 & 0.0208 & 0.0270 & 0.0181 \\
\hline $\mathrm{C} 13$ & 0.4291 & 0.5763 & 0.4089 & 0.5626 & 0.0222 & 0.0298 & 0.0212 & 0.0291 & 0.0298 & 0.0212 \\
\hline C14 & 0.4065 & 0.5820 & 0.5361 & 0.4568 & 0.0084 & 0.0120 & 0.0110 & 0.0094 & 0.0120 & 0.0084 \\
\hline SS1 & 0.4458 & 0.5452 & 0.4824 & 0.5208 & 0.0140 & 0.0171 & 0.0152 & 0.0164 & 0.0171 & 0.0140 \\
\hline SS2 & 0.4661 & 0.5290 & 0.5117 & 0.4910 & 0.0180 & 0.0205 & 0.0198 & 0.0190 & 0.0205 & 0.0180 \\
\hline SS3 & 0.3752 & 0.5727 & 0.5224 & 0.5083 & 0.0122 & 0.0187 & 0.0170 & 0.0166 & 0.0187 & 0.0122 \\
\hline IN1 & 0.3968 & 0.6302 & 0.4959 & 0.4467 & 0.0135 & 0.0215 & 0.0169 & 0.0152 & 0.0215 & 0.0135 \\
\hline IN2 & 0.3501 & 0.6505 & 0.4821 & 0.4710 & 0.0109 & 0.0202 & 0.0150 & 0.0146 & 0.0202 & 0.0109 \\
\hline IN3 & 0.3958 & 0.6374 & 0.4656 & 0.4693 & 0.0156 & 0.0251 & 0.0183 & 0.0185 & 0.0251 & 0.0156 \\
\hline IN4 & 0.3857 & 0.6298 & 0.4737 & 0.4798 & 0.0129 & 0.0211 & 0.0158 & 0.0160 & 0.0211 & 0.0129 \\
\hline
\end{tabular}

TABLE 7: Ranking of the four higher institutions by the MCDM methods.

\begin{tabular}{|c|c|c|c|c|c|c|c|c|c|}
\hline $\begin{array}{l}\text { S/ } \\
\text { no }\end{array}$ & Alternatives & TOPSIS & Ranking & $\begin{array}{c}\text { Compensatory } \\
\text { AND } \\
\end{array}$ & Ranking & $\begin{array}{c}\text { Yager's min-max } \\
\text { Values } \\
\end{array}$ & Ranking & $\begin{array}{l}\text { OWA } \\
\text { values }\end{array}$ & Ranking \\
\hline 1. & $\begin{array}{c}\text { Higher Institution } \\
\text { A }\end{array}$ & 0.1595 & 4 & 0.0000720 & 4 & 2.2218 & 3 & 4.4604 & 4 \\
\hline 2. & Higher Institution B & 0.9702 & 1 & 0.0021611 & 1 & 2.6640 & 1 & 5.9875 & 1 \\
\hline 3. & $\begin{array}{c}\text { Higher Institution } \\
\text { C }\end{array}$ & 0.3416 & 3 & 0.0001701 & 3 & 2.2832 & 2 & 4.8436 & 3 \\
\hline 4. & $\begin{array}{c}\text { Higher Institution } \\
\text { D }\end{array}$ & 0.4307 & 2 & 0.0002781 & 2 & 2.0762 & 4 & 4.9791 & 2 \\
\hline
\end{tabular}

Such that

(1) $w_{i} \in(0,1)$

(2) $\sum_{i} w_{i}=1$

and where

$F\left(a_{1}, a_{2}, \ldots, a_{n}\right)=w_{1} b_{1}+w_{2} b_{2}, \cdots, w_{n} b_{n}$,

where $b_{i}$ is the ${ }_{\mathrm{i}}$ th largest element in the sequence $a_{1}, a_{2}, \ldots, a_{n}$."
The main concern of OWA is to rank the arguments $\left(a_{1}, a_{2}, \ldots, a_{n}\right)$ in descending order where $\left(a_{1}, a_{2}, \ldots, a_{n}\right)$ represents the performance values of each higher institution depicted in Table 5.

$V_{\mathrm{i}}$ represents the AHP-derived criteria weights where $V_{i} \in[0,1]$. Therefore, to evaluate the overall satisfaction of the institutions: 
(i) Tertiary institutions are organized distinctly as $\left(V_{i}\left(A_{i}\right) \mathrm{HI}\right)$ couples.

(ii) $A_{i}(\mathrm{HI}) \mathrm{s}$ are then lined up in descending order such that $b_{j}$ is the biggest $j$ th value of $A_{i}(\mathrm{HI})$. Consequently, $U_{j}$ represents the weight linked with the $j$ th biggest higher institution satisfaction, Then, $u_{j}$ will now be $V_{j}$ with respect to $b_{j}$ 's which are in descending order [35]. Now we have $n\left(u_{j}, b_{j}\right)$ couples.

(iii) The OWA weights relevant to this aggregation technique is defined as

$$
w_{j}=Q\left(\frac{S_{j}}{T}\right)-Q\left(\frac{S_{j-1}}{T}\right) \text {. }
$$

Here,

$$
\begin{gathered}
S_{j}=\sum_{k=1}^{j} U_{k}, \\
T=\sum_{k=1}^{n} u_{k} .
\end{gathered}
$$

Linguistic quantifier "Most" which is $Q(r)=r^{2}$ is employed in equation (21) to calculate the OWA weight, $w_{j}$

(iv) With the weights calculated, we could find $D(x)$ evaluation with respect to each alternative as

$$
D(x)=\sum_{j=1}^{n} b_{j} w_{j}\left(H_{i}\right) .
$$

The performance evaluation of Higher institution A, with the OWA, is shown in Table 8. Conclusively, the overall performance value for all four Higher Institutions using the OWA is shown in Table 7 and Figure 10.

\section{Discussion}

From Table 5, the best nonfuzzy performance for each higher institution (HI) with respect to the criteria is determined. This actually revealed the institution's strong and weak points in terms of quality of service. Figures 5-8 give a graphical picture of alternative institutions' performance against each criterion, respectively. From Figure 5, Alternative HIA has the strongest weight in TC6 with 6.13 performance weight and the weakest weight in IN2 with 2.95. This shows that HIA has to improve on the number of international lecturers/faculty and maintain its strength in the areas of prompt release of departmental schedules, exams, and results. This discovery further buttresses the importance of internationalisation in evaluating service quality of a higher institution of learning which is omitted in the HiEdQUAL service model [33]. For alternative HIB from Figure 6, the strongest point is AS1 with 6.06 weight, and the weakest point is AF5 with 2.95. This suggests that there is a need for this institution to improve its library academic resources and encourage the administrative staff to provide service without delay. Also, for alternative HIC from Figure 7, the strongest point is TC2 with 6.593 weight followed by TC5 with 6.39. This shows that greater percentage of this institution's faculty is following the curriculum and there is a positive impact of this in adding knowledge to its students as indicated by its TC5 performance. Nevertheless, there is a need for more international personnel (faculty) as indicated by its low weight in IN2. In the case of alternative HID as shown in Figure 8, its major strength lies in teaching and course content but no quality hostel facilities as indicated by its lower performance weight of 2.78 (C11).

In Table 1, Fuzzy AHP was used to derive overall weights for each criterion in Ext- HiEdQUAL service model based on pairwise comparison matrix of the experts' opinions and the graphical representative of the result is shown in Figure 9 for easy analysis. Figure 9 shows that Criterion 25 (University has adequate Amenities-Canteen, Shopping center, Bank, ATM, Post office, etc.) has the highest overall weight, followed by Criterion 24 (University has adequate medical facilities (Health centers)). The lowest weighted criterion was 16 (University has safety and security measures). This result indicates that in ranking universities in Nigeria, amenities and facilities are very important as indicated by the experts. For criterion 16, having the lowest weight shows the level of importance attributed to security and safety by the decisionmakers. Nevertheless, the institutions that were considered are not doing badly on the issues of safety and security. The security threats and terrorism in Nigeria could have motivated their performances.

Regarding the implementation, Fuzzy AHP was found to be highly cognitively demanding as this was in consonance with findings reported in Ref. [57]. The OWA had the second highest amount of computations and the TOPSIS is third, while the Yager's min-max was fourth and less demanding. The compensatory AND had the least amount of computation and was least cognitively demanding. In terms of conflicts in the results of the four MCDM methods, two perspectives can be determined. First, note the rate at which the best alternative is the same all through the four methods and second, note the rate at which the ranking of any alternative is different in any of the MCDM methods. The TOPSIS, OWA, the Compensatory AND, and the Yager's min-max fulfill this perspective by selecting Higher Institution $\mathrm{B}$ as the best; this is shown in Table 7 . In the second contradiction rate, the ranking result of the Yager's min-max for the second, third, and fourth placed higher institutions is opposing the other consensus ranking results. This indicates that even when the performance data from the decisionmakers are consistent, there can be different ranking results due to the unique aggregation processes involved. Figure 10 gives more insight to the performance of the alternatives; the performance of Alternative HIB is not just ranked first with all the four methods but with outstanding best performance compared with other institutions. For instance, according to TOPSIS, overall evaluation ranking result, shown in Table 7 , HIB is evaluated and ranked as the best alternative with the 0.97 coefficient of closeness to the ideal institution, even though there are still distinct rooms for improvement as revealed by Figure 8 . This is followed by HID with 0.43 


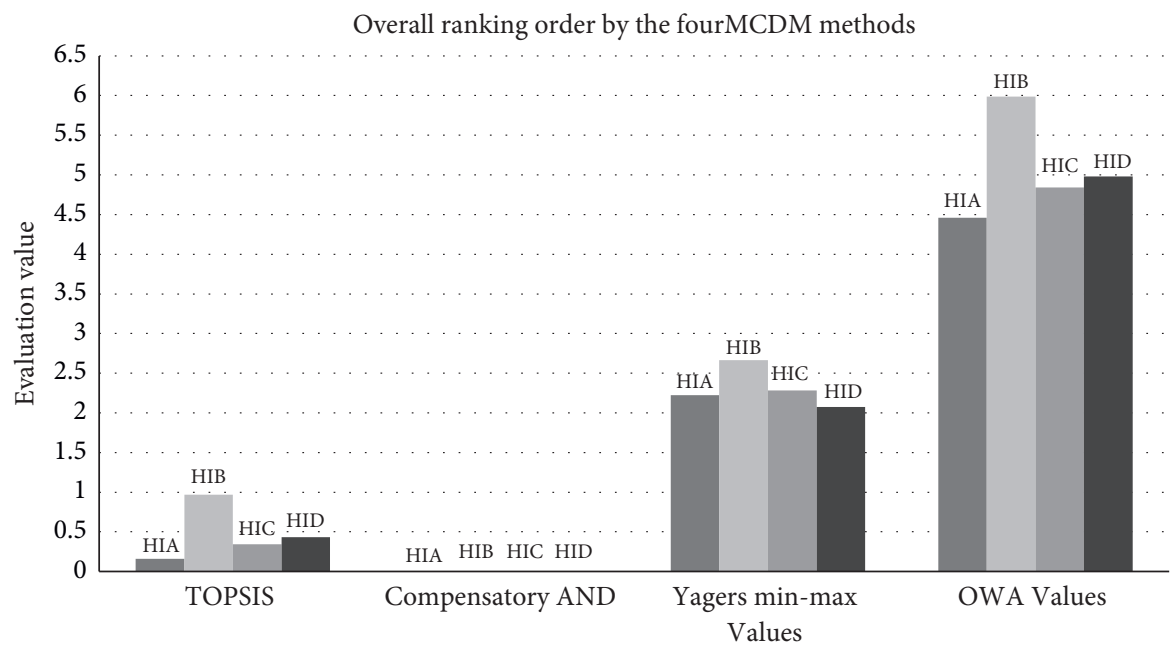

MCDM Methods

FIGURE 10: Graphical representation of the overall ranking process by the four MCDM methods.

TABLE 8: Yager's min-max criteria values of the four higher institutions (HI) and OWA generated weights and the overall performance value for higher institution $B$.

\begin{tabular}{|c|c|c|c|c|c|c|c|c|}
\hline \multirow[t]{2}{*}{ Criteria } & \multicolumn{4}{|c|}{$\begin{array}{l}\text { Yager's min-max criteria values of the four higher } \\
\text { institutions (HI) }\end{array}$} & \multicolumn{4}{|c|}{ OWA performance evaluation for higher institution A } \\
\hline & HI A & HI B & HI C & HI D & $V_{i}$ & $b_{i}$ & $w_{i}$ & $\mathrm{D}(\mathrm{HI} \mathrm{A})$ \\
\hline TC1 & 4.2136 & 5.1205 & 4.8610 & 4.8947 & 0.0387 & 6.12666666 & 0.001501 & 4.4604 \\
\hline TC2 & 4.431 & 5.0462 & 4.7328 & 4.4869 & 0.0249 & 6.086666666 & 0.002559 & \\
\hline TC3 & 4.9409 & 5.8472 & 5.2277 & 5.3268 & 0.0361 & 6.06 & 0.005905 & \\
\hline TC4 & 7.3687 & 8.5104 & 7.3294 & 8.5505 & 0.0283 & 5.78 & 0.006475 & \\
\hline TC5 & 11.6073 & 15.2673 & 13.6204 & 14.3456 & 0.0349 & 5.73333333 & 0.010198 & \\
\hline TC6 & 10.1563 & 12.2491 & 8.7787 & 9.3578 & 0.0347 & 5.72 & 0.012533 & \\
\hline TC7 & 5.1753 & 5.7882 & 4.3031 & 4.8165 & 0.0311 & 5.71333333 & 0.013309 & \\
\hline TC8 & 4.6690 & 5.5089 & 4.5623 & 5.3391 & 0.0426 & 5.70666666 & 0.021364 & \\
\hline TC9 & 5.2546 & 5.5213 & 5.1521 & 4.8242 & 0.0282 & 5.55333333 & 0.016144 & \\
\hline TC10 & 4.7799 & 6.0267 & 5.0459 & 5.4318 & 0.0261 & 5.52666666 & 0.016385 & \\
\hline AS1 & 2.5590 & 2.8854 & 2.5139 & 2.5910 & 0.0273 & 5.52666666 & 0.018563 & \\
\hline AS2 & 4.3769 & 4.8068 & 4.0097 & 4.1985 & 0.0255 & 5.49333333 & 0.018741 & \\
\hline AS3 & 4.3075 & 4.5954 & 4.2276 & 4.3821 & 0.0298 & 5.37333333 & 0.023481 & \\
\hline AS4 & 6.0050 & 6.1636 & 6.1420 & 5.8681 & 0.0158 & 5.2 & 0.013217 & \\
\hline AS5 & 7.5125 & 8.1720 & 7.9276 & 8.4788 & 0.0305 & 5.17333333 & 0.026920 & \\
\hline AS6 & 2.3695 & 2.7517 & 2.5936 & 2.4617 & 0.0270 & 5.14 & 0.025346 & \\
\hline AF1 & 2.2702 & 2.6640 & 2.2832 & 2.4943 & 0.0291 & 5.07333333 & 0.029012 & \\
\hline AF2 & 3.7212 & 5.7082 & 3.9328 & 4.8225 & 0.0311 & 4.93333333 & 0.032846 & \\
\hline AF3 & 5.2258 & 5.8565 & 4.6386 & 6.1046 & 0.0314 & 4.87333333 & 0.035120 & \\
\hline AF4 & 5.1603 & 7.1123 & 5.6484 & 6.2530 & 0.0517 & 4.8 & 0.062146 & \\
\hline AF5 & 8.5575 & 10.9974 & 8.0218 & 8.2667 & 0.0181 & 4.78666666 & 0.023094 & \\
\hline AF6 & 2.2218 & 2.7400 & 2.3181 & 2.2756 & 0.0387 & 4.5 & 0.051355 & \\
\hline $\mathrm{C} 11$ & 2.6795 & 3.8154 & 3.0169 & 2.0762 & 0.0161 & 4.49333333 & 0.022245 & \\
\hline $\mathrm{C} 12$ & 8.4697 & 15.1497 & 10.3117 & 10.3512 & 0.0166 & 4.45333333 & 0.023527 & \\
\hline C13 & 14.5951 & 24.1609 & 13.4371 & 23.1871 & 0.0437 & 4.386666666 & 0.064580 & \\
\hline C14 & 2.6474 & 3.3772 & 3.1945 & 2.8655 & 0.0205 & 4.2 & 0.031642 & \\
\hline SS1 & 5.1735 & 6.3753 & 5.6148 & 6.0795 & 0.0278 & 4.18666666 & 0.044149 & \\
\hline SS2 & 6.8279 & 8.0248 & 7.6918 & 7.2964 & 0.0326 & 4.08 & 0.053782 & \\
\hline SS3 & 4.5461 & 7.1674 & 6.4921 & 6.3035 & 0.0340 & 3.98 & 0.058453 & \\
\hline IN1 & 4.7296 & 7.9570 & 6.0768 & 5.4031 & 0.0217 & 3.96 & 0.038424 & \\
\hline IN2 & 3.0384 & 5.7370 & 4.2190 & 4.1197 & 0.0393 & 3.59333333 & 0.072078 & \\
\hline IN3 & 5.2649 & 9.7752 & 6.5005 & 6.5672 & 0.0334 & 3.36 & 0.063663 & \\
\hline IN4 & 3.8076 & 6.5404 & 4.7767 & 4.8448 & 0.0310 & 2.95333333 & 0.061227 & \\
\hline
\end{tabular}


TABLE 9: Distribution of sensitivity coefficients $\mathrm{SC}_{s}^{*}$.

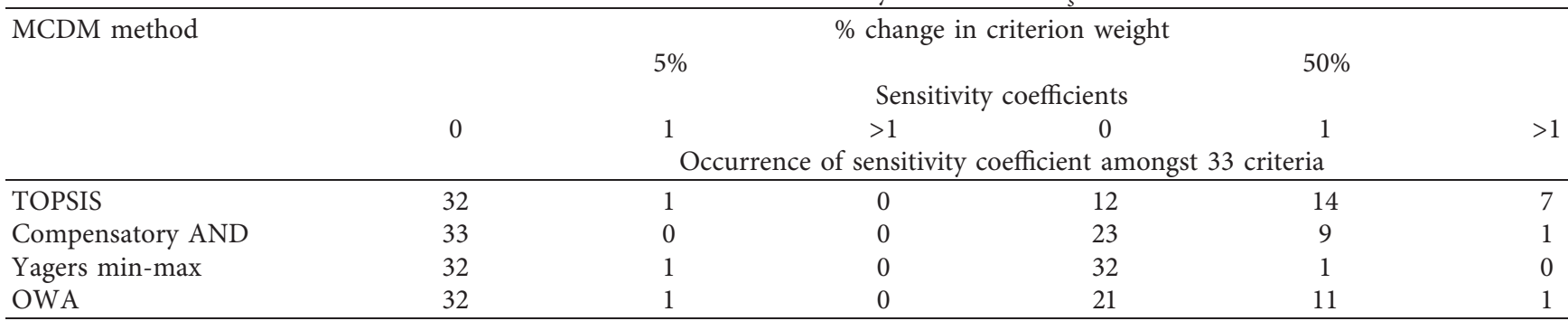

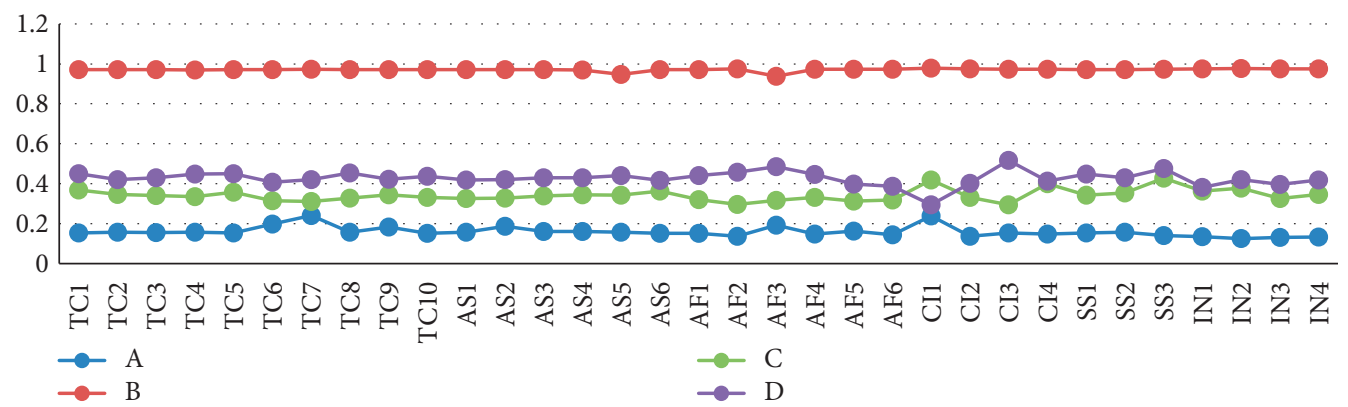

FIGURE 11: Performance sensitivity of the higher institution alternatives when criteria weights are increased by $5 \%$ for the TOPSIS method.

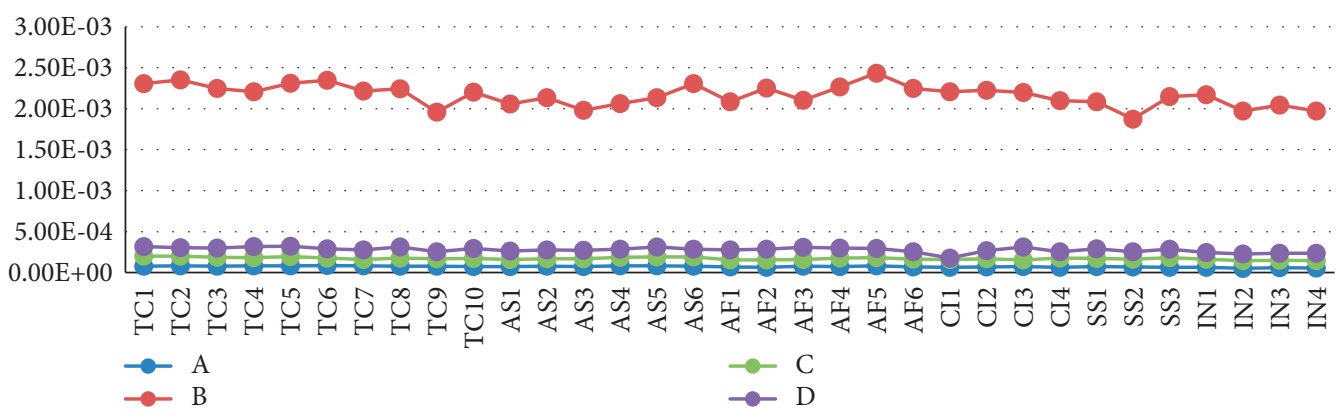

FIGURE 12: Performance sensitivity of the higher institution alternatives when criteria weights are increased by $5 \%$ for compensatory AND method.

coefficient of closeness, HIC with 0.34 and HIA are the farthest institutions from the Ideal with 0.16 coefficient of closeness.

\section{Sensitivity Analysis}

The deviation of each criterion weight is investigated to ascertain its impact on the ranking of the alternatives and the stability of each MCDM method. This deviation becomes paramount because the criteria weights are highly subjective, depending on the decision-makers' judgment. It depicts the robustness of the ranked alternatives by showing trends in performances as a consequence of the alteration of the criteria weights. Each criterion weight is separately altered by a certain percentage $(0.01-100 \%)$ which in turn results in the other criteria weights to be simultaneously changed in order to ensure a total of $100 \%$ when all criteria weights are added. Table 9 presents the distribution of sensitivity coefficients, $\mathrm{SC}_{s}^{*}$ for criterion $j$ for the four MCDM methods. In this work, the specific value of the sensitivity coefficient, $\mathrm{SC}_{j}^{*}$ for criterion $j$, imply that an increase by $5 \%$ or $50 \%$ leads to a single, or double or multiple changes in the ranked order of alternatives. Figures 11-18 depicts the sensitivity analysis of each individual criterion when increased by $5 \%$ and $50 \%$ accordingly for each of four methods: TOPSIS, Compensatory AND, Yager's min-max and OWA respectively.

With 5\% increase change in all criteria weight, the sensitivity analysis showed that the Compensatory AND outperformed the other MCDM methods considered in this study. It is more stable in its generated ranking order of alternatives ( $\mathrm{HIB}>\mathrm{HID}>\mathrm{HIC}>\mathrm{HIA}$ ), i.e. no change observed in the ranked order of alternatives after $5 \%$ increase in criteria weights which can be seen in Table 7 and Figure 13. In view of this, the Compensatory AND method revealed its tolerance to changes in $5 \%$ criteria weight increase as against the others. This shows that Compensatory AND should be 


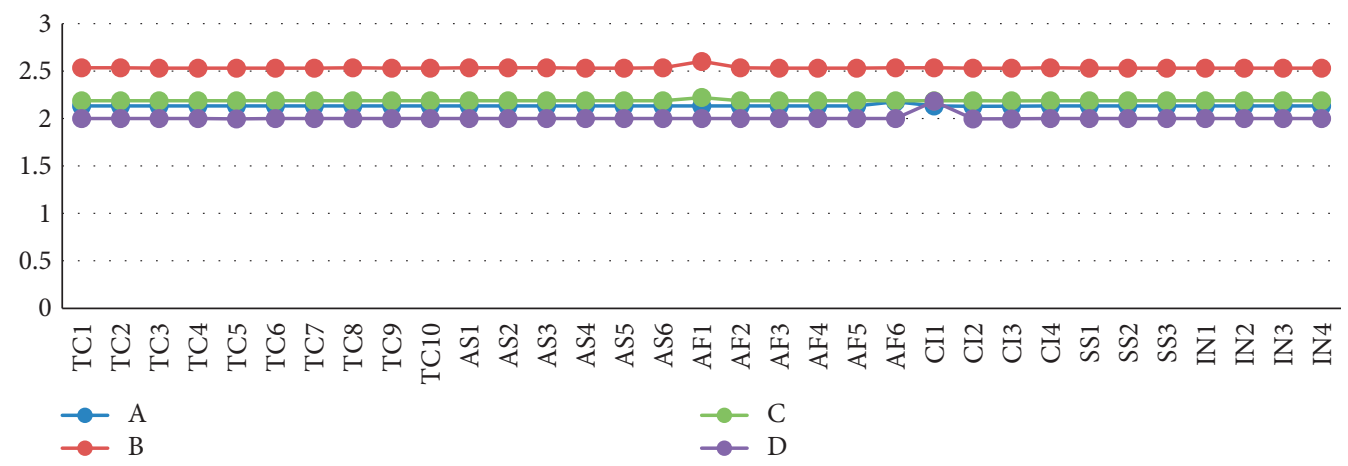

FIGURE 13: Performance sensitivity of the higher institution alternatives when criteria weights are increased by $5 \%$ for Yager's min-max method.

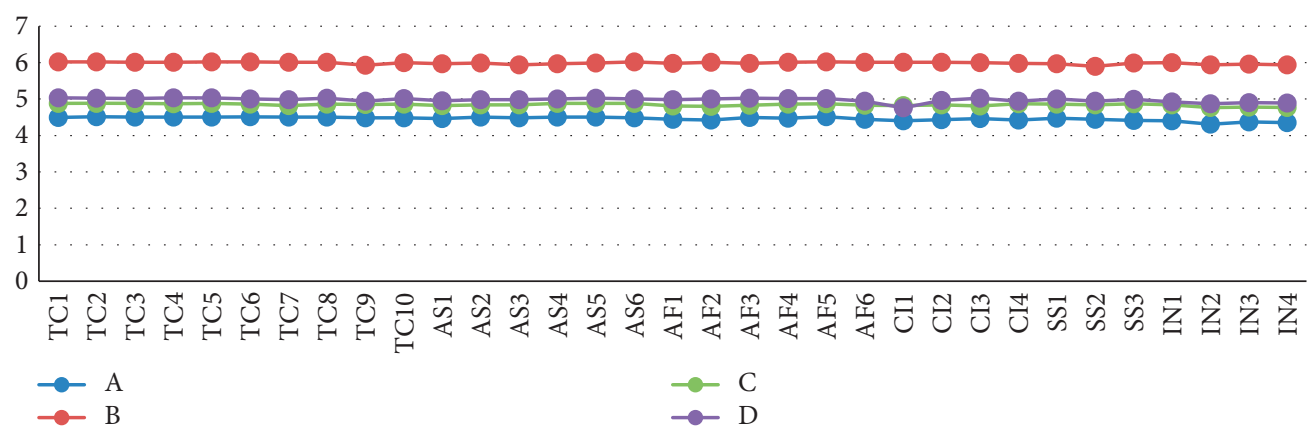

FIGURE 14: Performance sensitivity of the higher institution alternatives when criteria weights are increased by $5 \%$ for the OWA method.

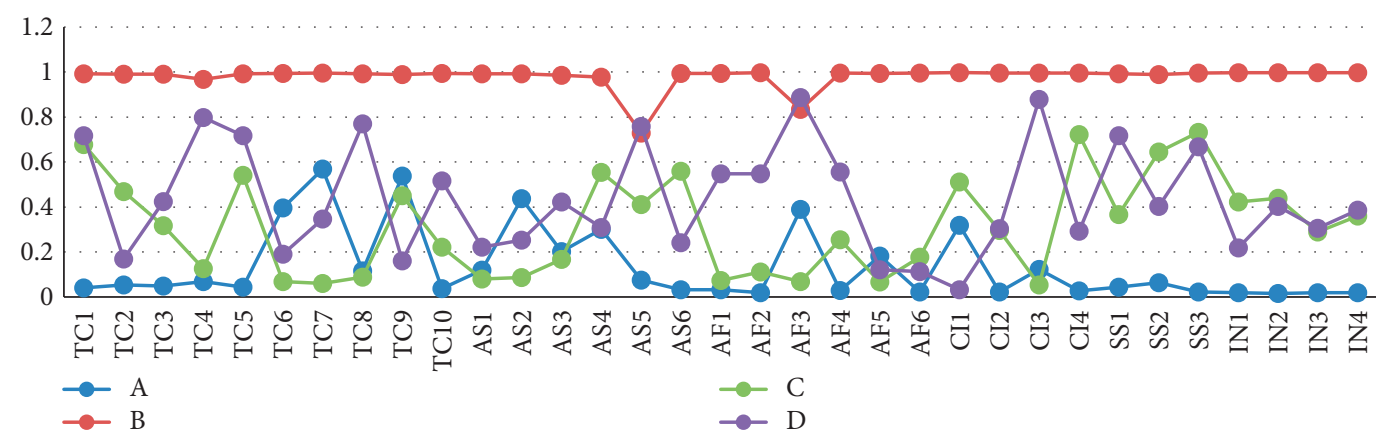

FIGURE 15: Performance sensitivity of the higher institution alternatives when criteria weights are increased by $50 \%$ for the TOPSIS method.

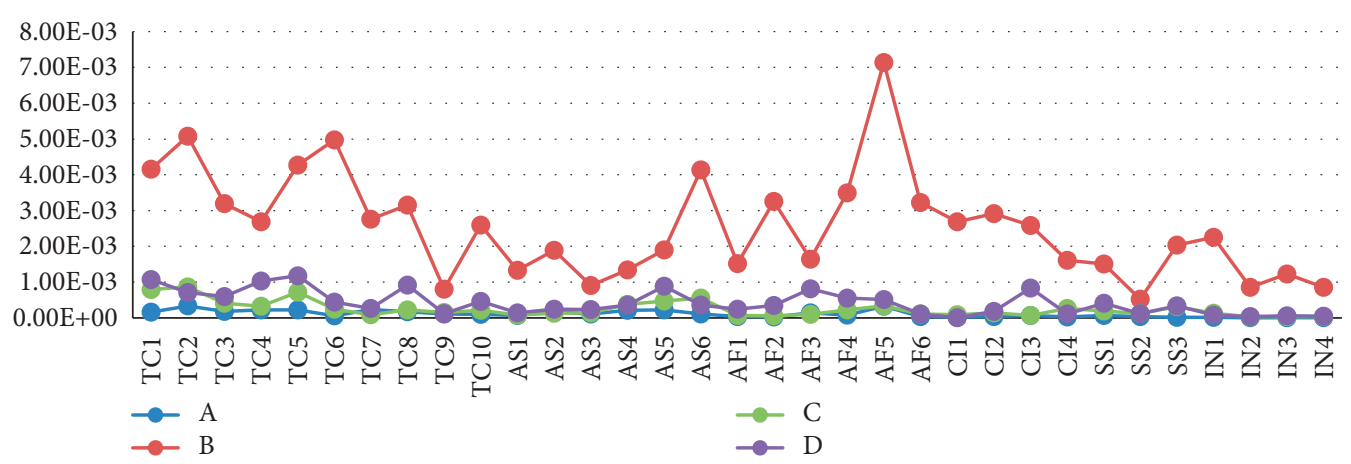

FIGURE 16: Performance sensitivity of the higher institution alternatives when criteria weights are increased by $50 \%$ for compensatory AND method. 


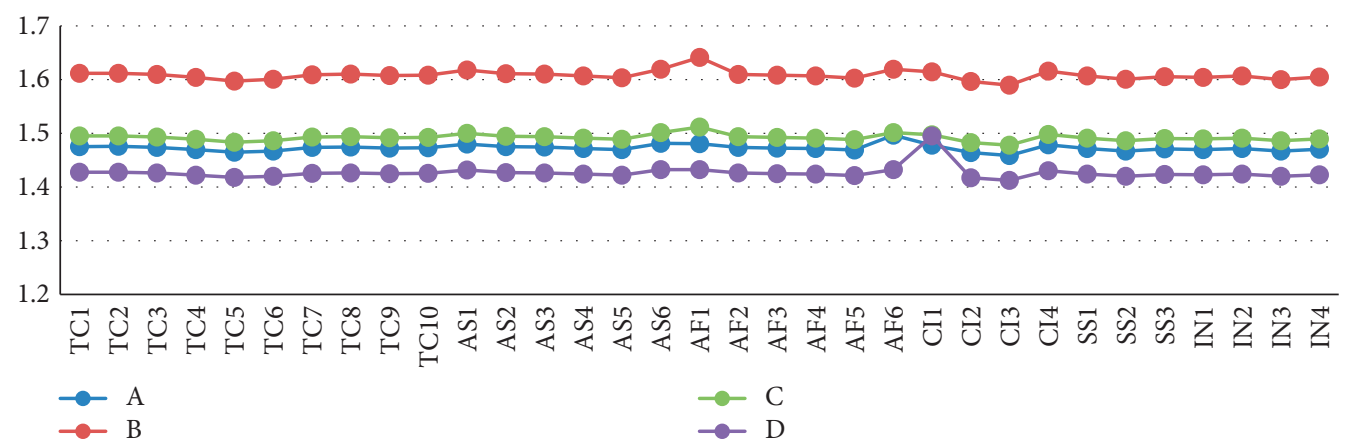

Figure 17: Performance sensitivity of the higher institution alternatives when criteria weights are increased by $50 \%$ for Yager's min-max method.

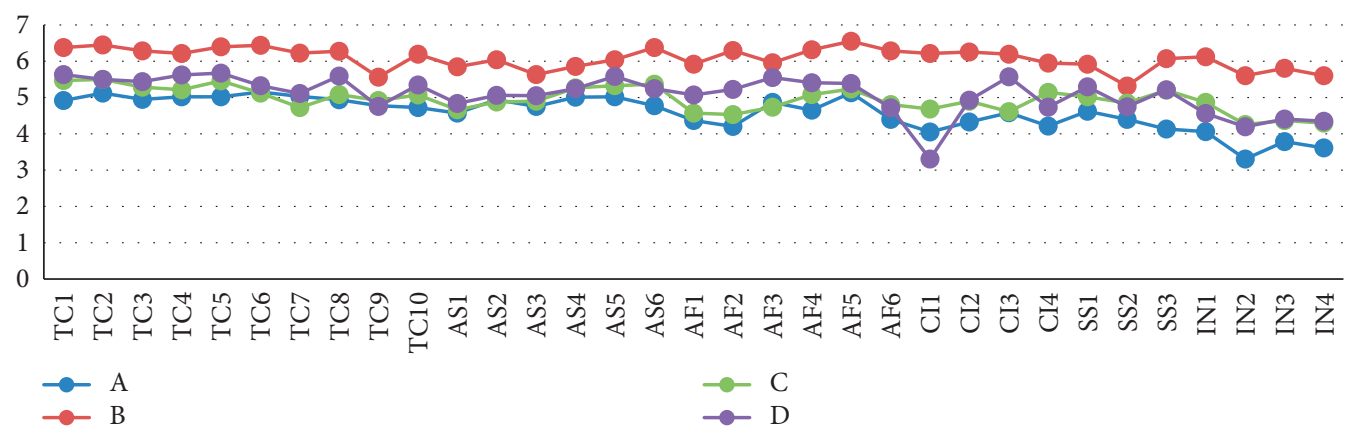

FIGURE 18: Performance sensitivity of the higher institution alternatives when criteria weights are increased by $50 \%$ for the OWA method.

considered when a minimal level of increase in criteria weights are needed. For other methods, 5\% increase change in criterion CI 1, changed the ranking order. For example, the TOPSIS order of ranking changed from original ranking order of $(\mathrm{B}>\mathrm{D}>\mathrm{C}>\mathrm{A})$ to $(\mathrm{HI} \mathrm{B}(0.9785)>\mathrm{HI} \mathrm{C}(0.4188)>$ HI D (0.2947) > HI A (0.2391)). This is shown in Table 7 and Figure 11

Meanwhile, when the increase of each individual criterion was at a higher level of 50\%, the sensitivity analysis graphs showed that the Yager's min-max can be adjudged to outperform the other methods: TOPSIS, Compensatory AND, OWA by being consistent and exceptionally tolerant in most instances than the other methods. For example, when each individual criterion was increased by $50 \%$, the Yager's min-max experienced only a single change in its ranked order of alternatives which was at CI1 as depicted in Figure 17 as against the original ranking in Table 7 . However, the number of criteria with unstable/changed order of alternatives increased considerably with the TOPSIS method which is adjudged the most inconsistent and intolerant as depicted in (Figure 15, Table 9). Also, in second place is the Compensatory AND as depicted in (Figure 16, Table 9) and the thirdly inconsistent is OWA in (Figure 18, Table 9).

In summary, the sensitivity analysis indicated that irrespective of the increase in weights by $5 \%$ or $50 \%$, Higher Institution B will always be the best ranked alternative, with the exception of the TOPSIS method in Figure 15 (with 50\% increase in AS5 and AF3), which is otherwise confirmed as the most unstable method in the comparative analysis. This established the robustness of the Higher Institution B as the best service rendering institution.

\section{Conclusion and Future Work}

This work presents a credible way to advance the status and reputation of higher institutions, by providing an approach for measuring quality of service in different institutions in a scientific manner. The approach presented in this study offers a reliable feedback system, which will enable the management of higher institutions to pay attention to their strengths and weak points in order to be properly positioned for improved service delivery and better global rankings among world universities. The investigation of the four MCDM (MAUT) methods, using the survey data, has been characterized through the ranking of the institutions and their respective computational procedure of combining data are explored. The robustness and reliability of the MCDM methods are identified and reinforced through their consistency in the ranking of the alternative institutions apart from the Yager's min-max, which yielded slightly different results. Also, Ext-HiEDQUAL domain-specific service quality model for evaluating higher institutions was introduced and employed for the evaluation, which gives more consideration to specific quality of service in institutions. In view of this, relevant decision was made on the best institution in the context of day-to-day services that higher institutions are expected to render in line with global and international practices. This study also reveals each 
institution's strong practice and weak practice to give room for improvement and good service delivery. Also, incorporating Fuzzy concept into the evaluation model injected a level of objectiveness in the decision-making process by capturing the intra-uncertainties of a decision-maker due to high level of subjectivity of the process. In future work, a higher level of objectiveness can be achieved in the decisionmaking process by incorporating enhanced interval type- 2 Fuzzy concept to MCDM approaches. This will enhance the robustness of the decisions by capturing both inter-uncertainty among different decision-makers and intra-uncertainties of a decision maker.

\section{Data Availability}

The dataset is a survey data from four institutions in Nigeria; it can only be released strictly on a formal request for verification.

\section{Conflicts of Interest}

No conflicts of interest.

\section{Acknowledgments}

The authors are grateful to the Covenant University for providing conducive environment and adequate support for carrying out this research work.

\section{References}

[1] R. Asiyai, "Challenges of quality in higher education in Nigeria in 21st century," International Journal of Educational Planning \& Administration, vol. 3, no. 2, pp. 159-172, 2013.

[2] B. Donaldson and C. McNicholas, "Understanding the postgraduate education market for UK-based students: a review and empirical study," International Journal of Nonprofit and Voluntary Sector Marketing, vol. 9, no. 4, pp. 346-360, 2004.

[3] A. Parasuraman, V. A. Zeithaml, and L. L. Berry, "A conceptual model of service quality and its implications for future research," Journal of Marketing, vol. 49, no. 4, pp. 41-50, 1985.

[4] R. R. Yager, "On ordered weighted averaging aggregation operators in multicriteria decisionmaking," IEEE Transactions on systems, Man, and Cybernetics, vol. 18, no. 1, pp. 183-190, 1988.

[5] D. Qiao, K.-w. Shen, J.-q. Wang, and T.-1. Wang, "Multicriteria PROMETHEE method based on possibility degree with Z-numbers under uncertain linguistic environment," Journal of Ambient Intelligence and Humanized Computing, vol. 11, no. 5, pp. 2187-2201, 2020.

[6] E. K. Zavadskas, Z. Turskis, and S. Kildiene, "State of art surveys of overviews on MCDM/MADM methods," Technological and Economic Development of Economy, vol. 20, no. 1, pp. 165-179, 2014.

[7] E. Mulliner, N. Malys, and V. Maliene, "Comparative analysis of MCDM methods for the assessment of sustainable housing affordability," Omega, vol. 59, pp. 146-156, 2016.

[8] L. Wang, X.-k. Wang, J.-j. Peng, and J.-q. Wang, "The differences in hotel selection among various types of travellers: a comparative analysis with a useful bounded rationality behavioural decision support model," Tourism Management, vol. 76, 2020.

[9] W. Xingli and L. Huchang, "A consensus-based probabilistic linguistic gained and lost dominance score method," European Journal of Operational Research, vol. 272, no. 3, pp. 1017-1027, 2019.

[10] Ž. Stevića, D. Pamučar, A. Puška, and P. Chatterjee, "Sustainable supplier selection in healthcare industries using a new MCDM method: measurement of alternatives and ranking according to Compromise solution (MARCOS)," Computers \& Industrial Engineering, vol. 140, 2020.

[11] G. H. Tzeng and J. J. Huang, Fuzzy Multiple Objective Decision Making, CRC Press, Boca Raton, FL, USA, 2013.

[12] J. Lu, G. Zhang, D. Ruan, and F. Wu, Multi-Objective Group Decision Making: Methods, Software and Applications with Fuzzy Set Techniques, World Scientific, Singapore, 2007.

[13] D. Kannan, S. Moazzeni, S. mostafayi Darmian, and A. Afrasiabi, "A hybrid approach based on MCDM methods and Monte Carlo simulation for sustainable evaluation of potential solar sites in east of Iran," Journal of Cleaner Production, vol. 279, 2020.

[14] H.-Y. Wu, J.-K. Chen, I.-S. Chen, and H.-H. Zhuo, "Ranking universities based on performance evaluation by a hybrid MCDM model," Measurement, vol. 45, no. 5, pp. 856-880, 2012.

[15] R. Aliyev, H. Temizkan, and a. R. Aliyev, "Fuzzy analytic hierarchy process-based multi-criteria decision making for universities ranking," Symmetry, vol. 12, no. 8, pp. 1-15, 2020.

[16] J. M. Vinotha, "Analytic hierarchy process and TOPSIS method to evaluate the performance of schools," International Journal in IT and Engineering, vol. 3, no. 3, pp. 29-37, 2015.

[17] C. Giannoulis and A. Ishizaka, "A web-based decision support system with ELECTRE III for a personalised ranking of British universities," Decision Support Systems, vol. 48, no. 3, pp. 488-497, 2010.

[18] S. Nisel and R. Nisel, "Using VIKOR methodology for ranking universities by academic performance," in Proceedings of the International Conference on Operations Research and Statistics (ORS), Singapore, 2013.

[19] M. Erdoğan and I. Kaya, "A type-2 fuzzy MCDM method for ranking private universities in İstanbul," in Proceedings of the World Congress on Engineering, London, UK, 2014.

[20] J. J. Cronin Jr. and S. A. Taylor, "Measuring service quality: a reexamination and extension," Journal of Marketing, vol. 56, no. 3, pp. 55-68, 1992.

[21] F. Abdullah, "The development of HEdPERF: a new measuring instrument of service quality for the higher education sector," International Journal of Consumer Studies, vol. 30, no. 6, pp. 569-581, 2006.

[22] N. Senthilkumar and A. Arulraj, "SQM-HEI - determination of service quality measurement of higher education in India," Journal of Modelling in Management, vol. 6, no. 1, pp. 60-78, 2011.

[23] M. Chavan, J. Bowden-Everson, E. Lundmark, and J. Zwar, "Exploring the drivers of service quality perceptions in the tertiary education sector," Journal of International Education in Business, vol. 7, no. 2, pp. 150-180, 2014.

[24] S. K. Jain and G. Gupta, "Measuring service quality: SERVQUAL vs. SERVPERF scales," Vikalpa: The Journal for Decision Makers, vol. 29, no. 2, pp. 25-38, 2004.

[25] A. Athiyaman, "Linking student satisfaction and service quality perceptions: the case of university education," European Journal of Marketing, vol. 31, no. 7, pp. 528-540, 1997. 
[26] G. LeBlanc and N. Nguyen, "Searching for excellence in business education: an exploratory study of customer impressions of service quality," International Journal of Educational Management, vol. 11, no. 2, pp. 72-79, 1997.

[27] S. Annamdevula and R. S. Bellamkonda, "Development of HiEdQUAL for measuring service quality in Indian higher education sector," International Journal of Innovation, Management and Technology, vol. 3, no. 4, pp. 412-416, 2012.

[28] M. Abidin, "Higher education quality: perception differences among internal and external stakeholders," International Education Studies, vol. 8, no. 12, pp. 185-192, 2015.

[29] A. Shekarchizadeh, A. Rasli, and H. Hon-Tat, "SERVQUAL in Malaysian universities: perspectives of international students," Business Process Management Journal, vol. 17, no. 1, pp. 67-81, 2011.

[30] R. I. Asiyai, "Improving quality higher education in Nigeria: the roles of stakeholders," International Journal of Higher Education, vol. 4, no. 1, pp. 61-70, 2015.

[31] J. S. Dodgson, M. Spackman, A. Pearman, and L. D. Phillips, Multi-Criteria Analysis: A Manual, Department for Communities and Local Government, London, UK, 2009.

[32] E. Triantaphyllou, Multi-Criteria Decision Making Methods: A Comparative Study, Springer Science \& Business Media, Berlin, Germany, 2000.

[33] J. Antucheviciene, A. Zakarevicius, and E. K. Zavadskas, "Measuring congruence of ranking results applying particular MCDM methods," Informatica, vol. 22, no. 3, pp. 319-338, 2011.

[34] L. A. Zadeh, "Fuzzy sets," Information and Control, vol. 8, no. 3, pp. 338-353, 1965.

[35] H. Akdag, T. Kalaycı, S. Karagöz, H. Zülfikar, and D. Giz, "The evaluation of hospital service quality by fuzzy MCDM," Applied Soft Computing, vol. 23, pp. 239-248, 2014.

[36] Y. Peng, G. Kou, G. Wang, and Y. Shi, "FAMCDM: a fusion approach of MCDM methods to rank multiclass classification algorithms," Omega, vol. 39, no. 6, pp. 677-689, 2011.

[37] S. Zha, Y. Guo, S. Wang, and S. Wan, "A hybrid MCDM method using combination weight for the selection of facility layout in the manufacturing system: a case study," Mathematical Problems in Engineering, vol. 2020, Article ID 1320173, 16 pages, 2020.

[38] J. Markovic Brankovic, M. Markovic, and D. Nikolic, "Comparative study of hydraulic structures alternatives using promethee II complete ranking method," Water Resources Management, vol. 32, no. 10, pp. 3457-3471, 2018.

[39] P. Ma, N. Yao, and X. Yang, "Service quality evaluation of terminal express delivery based on an integrated SERVQUAL-AHP-TOPSIS approach," Mathematical Problems in Engineering, vol. 2021, Article ID 8883370, 10 pages, 2021.

[40] F. Zhou, X. Wang, M. K. Lim, Y. He, and L. Li, "Sustainable recycling partner selection using fuzzy DEMATEL-AEWFVIKOR: a case study in small-and-medium enterprises (SMEs)," Journal of Cleaner Production, vol. 196, pp. 489-504, 2018.

[41] F. Zhou, M. K. Lim, Y. He, and S. Pratap, "What attracts vehicle consumers' buying: a Saaty scale-based VIKOR (SSCVIKOR) approach from after-sales textual perspective?" Industrial Management \& Data Systems, vol. 120, no. 1, pp. 57-78, 2020.

[42] L. Ikuvwerha, T. Amoo, V. Odumuyiwa, and O. Oladipupo, "Enhancing business decision making through actionable knowledge discovery using an hybridized MCDM model," in Proceedings of the International Conference on
E-Infrastructure and E-Services for Developing Countries, Lagos, Nigeria, 2018.

[43] O. S. Ohunakin and B. O. Saracoglu, "A comparative study of selected multi-criteria decision-making methodologies for location selection of very large concentrated solar power plants in Nigeria," African Journal of Science, Technology, Innovation and Development, vol. 10, no. 5, pp. 551-567, 2018.

[44] I. P. Okokpujie, U. C. Okonkwo, C. A Bolu, O. S Ohunakin, M. G. Agboola, and A. A. Atayero, "Implementation of multicriteria decision method for selection of suitable material for development of horizontal wind turbine blade for sustainable energy generation," Heliyon, vol. 6, no. 1, Article ID e03142, 2020.

[45] A. Mardani, A. Jusoh, and E. K. Zavadskas, "Fuzzy multiple criteria decision-making techniques and applications - two decades review from 1994 to 2014," Expert Systems with Applications, vol. 42, no. 8, pp. 4126-4148, 2015.

[46] A. U. Angitha and M. Supriya, "Ranking of educational institutions based on user priorities using AHP-PROMETHEE approach," in Advances in Computing and Network Communications, pp. 127-142, Springer, Singapore, 2021.

[47] D. Dubois and H. Prade, "Operations on fuzzy numbers," International Journal of Systems Science, vol. 9, no. 6, pp. 613-626, 1978.

[48] J. J. Buckley, "Ranking alternatives using fuzzy numbers," Fuzzy Sets and Systems, vol. 15, no. 1, pp. 21-31, 1985.

[49] R. A. Ribeiro, "Fuzzy multiple attribute decision making: a review and new preference elicitation techniques," Fuzzy Sets and Systems, vol. 78, no. 2, pp. 155-181, 1996.

[50] D. T. Pham and M. Castellani, "Action aggregation and defuzzification in Mamdani-type fuzzy systems," Proceedings of the Institution of Mechanical Engineers-Part C: Journal of Mechanical Engineering Science, vol. 216, no. 7, pp. 747-759, 2002.

[51] T. L. Saaty, The Analytic Hierarchy Process: Planning, Priority Setting, McGrawHill, New York, NY, USA, 1980.

[52] A. Ishizaka and P. Nemery, Multi-Criteria Decision Analysis: Methods and Software, John Wiley \& Sons, Hoboken, NJ, USA, 2013.

[53] C. Hwang and K. Yoon, Multiple Attribute Decision Making: Methods and Application, Springer-Verlag, New York, NY, USA, 1981.

[54] H.-J. Zimmermann and P. Zysno, "Latent connectives in human decision making," Fuzzy Sets and Systems, vol. 4, no. 1, pp. 37-51, 1980.

[55] V. Ravi and P. J. Reddy, "Ranking of Indian coals via fuzzy multi attribute decision making," Fuzzy Sets and Systems, vol. 103, no. 3, pp. 369-377, 1999.

[56] R. R. Yager, "Fuzzy decision making including unequal objectives," Fuzzy Sets and Systems, vol. 1, no. 2, pp. 87-95, 1978.

[57] M. Cinelli, S. R. Coles, and K. Kirwan, "Analysis of the potentials of multi criteria decision analysis methods to conduct sustainability assessment," Ecological Indicators, vol. 46, pp. 138-148, 2014. 